ISSN: 0213-2079 - ISSN electrónico: 2386-3889

DOI: http://dx.doi.org/10.14201/shhmo2016381155192

\title{
TRANSGRESIÓN Y LEGALIDAD EN EL CORTEJO DEL SIGLO XVIII: EL SECUESTRO DE MUJERES EN LA DIÓCE- SIS DE ZARAGOZA"
}

\section{Offence and Legality in the 18th Century Courtship: the Abduction of Women on the Bishopric of Zaragoza}

\author{
Daniel BALDELLOU \\ Universidad de Zaragoza \\ Correo-e: dsbaldellou@hotmail.com
}

RESUMEN: Este artículo analiza la conflictividad generada en las familias españolas del siglo XviII a raíz del proceso de secuestro. El «secuestro» se trataba de un recurso legal dependiente del tribunal eclesiástico que permitía a las jóvenes comprometidas ser extraídas de su hogar en caso de que su familia les impidiese el matrimonio planeado. En el caso de la diócesis de Zaragoza, este recurso de secuestro venía acompañado también por los procesos de Manifestación, dependientes de los fueros aragoneses y cuyo funcionamiento permitía este mismo proceso con distintos resultados. Secuestros y manifestaciones constituían una herramienta de presión que las parejas utilizaban frente a una autoridad paterna que era considerada natural pero, no por ello, ilimitada. A lo largo del artículo desglosamos el proceso legal del secuestro y de la manifestación, además de analizar cuál era el impacto emocional que tenía en la familia y la comunidad la salida de una hija soltera de la autoridad paterna.

Palabras clave: Zaragoza; cortejo; secuestro; proceso de manifestación; conflicto familiar; autoridad familiar.

* Este trabajo se ha realizado en el marco del Proyecto de Investigación financiado por el Ministerio de Economía, Ciencia e Innovación con la siguiente referencia HAR2012-34576.

(C) Ediciones Universidad de Salamanca / ®@ Stud. his., H. ${ }^{a}$ mod., 38, n. 1 (2016), pp. 155-192 
ABSTRACT: The article analyses the conflict generated in 18th Century Spanish families based on the impeachment of «Secuestro». Secuestro was a legal procedure depending on the Church Court that allowed young single women to be extracted from their parent's home. This extraction was executed when the family forbade the marriage without a fair argument. In the bishopric of Zaragoza, this procedure was accompanied by the privilege of Manifestación, depending on the Aragonian old laws. The Manifestación allowed the same extraction, although the results were sometimes very different. Those procedures became an important resource for those young couples who rebelled against the father's authority, which was deeply respected but not boundless. Along this article, I bring the steps of these legal procedures. Besides, I analyse which emotional impact had on families and communities the egress of a single girl for the paternal authority.

Key words: Zaragoza; Courtship; Abduction; «Manifestación»; Family Conflict; Family Authority.

\section{INTRODUCCIÓN: EL MATRIMONIO DE BUENA LEY}

El proceso regalista del siglo xvin tuvo como objetivo el afianzamiento de una única autoridad real frente a la multiplicidad de poderes característicos del Antiguo Régimen. Esta concepción política no se trataba ni mucho menos de una novedad, lo que sí constituyó una innovación en el Reino de España fue el intento de implantar esta ideología a la vez que se utilizaba la más primigenia estructura de poder, la familia, como representación e incluso justificación del poder absoluto. La aplicación de una serie de Pragmáticas y reales cédulas iniciadas en 1776 intentó impulsar la autoridad de padres y tutores en el seno familiar. Fue el incremento de la noción de libertad individual lo que hizo imperativo consolidar la autoridad paterna. De entre los problemas familiares directamente relacionados con la estabilidad social, la libertad matrimonial de los descendientes frente a sus padres cobró una extraordinaria relevancia para la España de la Ilustración ${ }^{1}$.

Frente a la iniciativa borbónica de 1776 para incrementar la autoridad paterna, el principio legal al que los matrimonios católicos debían adherirse era el derecho canónico. En el Concilio de Trento se consagró la necesidad de acceder al matrimonio libremente y la imposibilidad de vetarlo sin razón justificada. Frente a la

1. Chacón Jiménez, F. y Méndez Vázquez, J.: «Miradas sobre el matrimonio en la España del último tercio del siglo XviII", Cuadernos de Historia Moderna, 32, 2007, pp. 61-85.

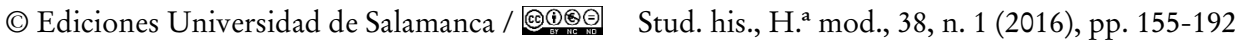


DANIEL BALDELLOU

TRANSGRESIÓN Y LEGALIDAD EN EL CORTEJO DEL SIGLO XVIII:

EL SECUESTRO DE MUJERES EN LA DIÓCESIS DE ZARAGOZA

tendencia observada en el despotismo ilustrado, los tribunales eclesiásticos fueron a lo largo de los siglos XVII y XVIII los principales valedores de este principio de libertad de matrimonio ${ }^{2}$.

Es importante señalar, en primer lugar, que la tensión entre matrimonio libre y matrimonio tutelado por la familia no desembocaba en un conflicto permanente. En la mayoría de las ocasiones se trataba de un juego de estrategias en el que cada parte planteaba sus prioridades y jugaba sus bazas para obtener el mejor resultado posible. A este respecto, las estrategias familiares reflejadas en los pleitos por esponsales, estupro o los casos de secuestro y manifestación que nos ocupan deben entenderse como solo una porción de los conflictos en el camino al matrimonio, por regla general resueltos mediante pactos infrajudiciales ${ }^{3}$.

En cuanto a la resolución de conflictos en el camino al matrimonio, la historiografía italiana de las dos últimas décadas ha realizado importantes aportaciones al estudio de los aspectos conflictivos de la vida familiar «interpretándolos no como desviaciones, sino como parte integrante de la experiencia vital» ${ }^{4}$. Los estudios realizados por esta escuela se han centrado en la abundante documentación procesal eclesiástica de las diócesis italianas como fuente principal. En dichos procesos quedaron reflejadas estas tensiones familiares de las que la iglesia ejercía como árbitro preferente 5 .

2. La importancia de los tribunales eclesiásticos en materia de libertad matrimonial ha quedado evidenciada por las investigaciones de Seidel Menchi, S.: «La Svolta di Trento. Ricerche Italiane sui processi matrimoniali», Popolazione e storia, 2004, 2, pp. 21-32. GAUDEMET, J.: El matrimonio en occidente. Madrid, 1993, pp. 30-45 y 240-261 y Lorenzo Pinar, F. J.: «Conflictividad social en torno a la formación del matrimonio (Zamora y Toro en el siglo XVI», Studia Historica. Historia Moderna, 13, 1995, pp. 131-154.

3. Sobre el concepto de «infrajudicialidad» y la resolución de conflictos sin permitir que llegasen ante los tribunales véase Mantecón Tomás, A.: «El peso de la infrajudicialidad en el control del crimen durante la Edad Moderna», Estudis: Revista de Historia Moderna, 28, 2002, pp. 43-76.

4. LOMBARDI, D.: «Privilegios jurídicos y relaciones de vecindad en la formación de la pareja en la Italia Moderna», Obradoiro de Historia Moderna, 21, 2012, pp. 9-27. Ferrante, L.: «L'onore ritrovato. Donne nella Casa de Socorso di San Paolo de Bologna (sec. XVI-XVII)», Quaderni Storici, 53, 1983, pp. 500-523.

5. Destacamos especialmente de esta historiografía los trabajos de Ferraro, J. M.: Marriage Wars in Late Renaissance Venice. Oxford, 2001. Lombardi, D.: Matrimoni di antico regime. Bologna, Il Mulino, 2001; LANzInger, M. y SARTI, R.: Nubili e Celibi tra scelta e costrizione (Secoli $X V I-X X)$. Udine: 2006. En una línea similar de esta escuela italiana hay que destacar también los trabajos de Ingram, M.: Church Courts, Sex and Marriage in England, 1570-1640. Cambridge. 1987; Candau Chacón, M. ${ }^{a}$ L.: «Entre lo permitido y lo ilícito: la vida afectiva en los Tiempos Modernos», Tiempos Modernos, 18, 2009, pp. 11-17; UsunárIz GaraYOA, J. M.a: «La violencia doméstica en la España de los siglos XVI y XviI: el ejemplo del reino de Navarra», en Escudero, J. M. y Roncero, V. (coord.): La violencia en el mundo hispánico en el Siglo de Oro. Madrid, 2010, pp. 375-394.

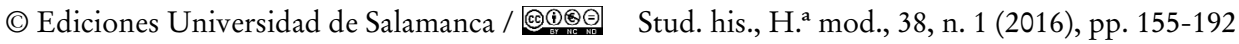




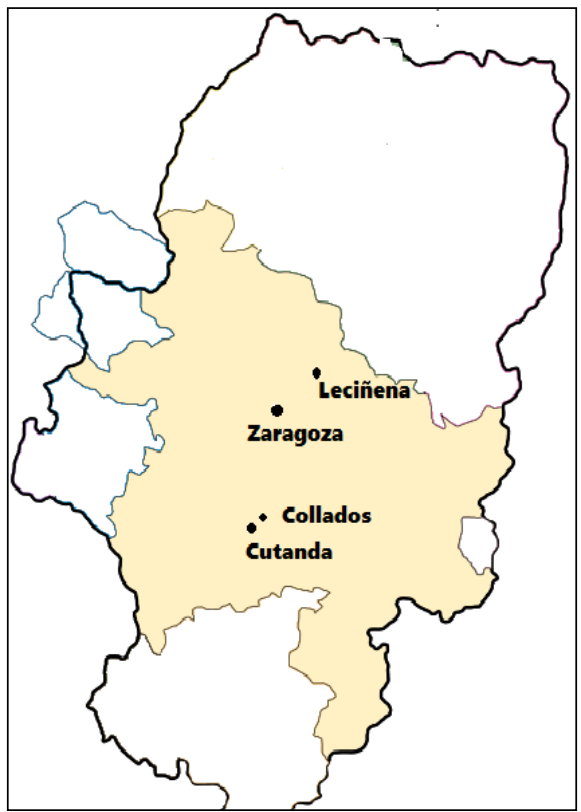

Figura 1: Archidiócesis de Zaragoza en el siglo XviII y localidades citadas a lo largo del artículo ${ }^{6}$.

A lo largo de este artículo, se profundiza en los procesos legales de secuestro y manifestación. Dos recursos mediante los cuales una pareja podía imponer su proyecto matrimonial por encima de la opción de sus familias en la diócesis de Zaragoza. El secuestro eclesiástico se trataba de un proceso vinculado a los tribunales diocesanos, mientras que la manifestación era un procedimiento propio de los fueros de Aragón. Sus raíces eran distintas, pero a la altura del siglo xviII ambos eran utilizados con intensidad para dirimir conflictos sobre las estrategias matrimoniales. El fundamento justificativo de ambos estaba en ejercicio de la autoridad: se trataban de dos procedimientos mediante los cuales se podía extraer a un individuo de la tutela a la que estaba asignado y reubicarlo bajo la autoridad temporal de un poder mediador que determinase si se había ejercido un abuso. En ambos casos, los tribunales actuaban ante la sospecha de presiones o compromisos forzosos. La principal diferencia estribaba en los límites que cada autoridad juzgaba oportunos para la autoridad paterna sobre los hijos.

6. Espacio demarcado como diócesis de Zaragoza a la altura del siglo xviı. Mapa de elaboración propia.

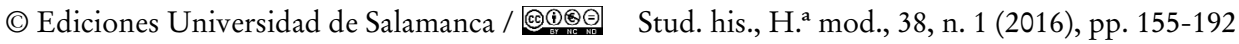


DANIEL BALDELLOU

TRANSGRESIÓN Y LEGALIDAD EN EL CORTEJO DEL SIGLO XVIII:

EL SECUESTRO DE MUJERES EN LA DIÓCESIS DE ZARAGOZA

\section{LOS PROCESOS JUDICIALES DE SECUESTRO Y MANIFESTACIÓN}

Como principal adalid del libre albedrío, el tribunal diocesano de Zaragoza utilizó con intensidad el recurso de secuestro para extraer a mujeres solteras de sus casas a petición de sus novios o de ellas mismas. El tribunal diocesano de Zaragoza cuenta con un total de 454 procesos por secuestro desarrollados a lo largo del siglo XVIII, la mayoría de los mismos dirigidos exclusivamente a apartar doncellas de sus hogares e interrogarlas sobre cuál era su deseo. Los ligámenes en los que se organizaban estos secuestros no están completos, por lo que es probable que hubiese más casos de secuestros. Dado que no contamos con un registro completo, no hay forma de saber con exactitud los números totales, pero sí podemos certificar la importancia reconocida a los mismos tanto por la cantidad de procesos conservados como por la falta de reclamaciones tras su ejecución ${ }^{7}$.

\begin{tabular}{|l|c|}
\hline Secuestros según el objetivo & Casos \\
\hline Mujer comprometida & 233 \\
\hline Mujer casada & 100 \\
\hline Bienes muebles o beneficios eclesiásticos & 75 \\
\hline Causa criminal & 46 \\
\hline
\end{tabular}

Figura 2: tipología de los procesos de secuestro según su objetivo ${ }^{8}$.

Originalmente, el acto de «sequestro» se trataba de un «depósito judicial que se hace en un tercero de alguna alhaja litigiosa, hasta que se decida à quien pertenece» ${ }^{9}$. Se trataba por lo tanto de una mediación en la que se retiraba al

7. No se pretende bajo ningún concepto establecer un estudio sobre el número de casos, los pleitos presentados en el tribunal son aquellos que se llevaban ante una autoridad jurídica y es importante no confundirlos con la conflictividad total. IgLesias Estepa, R.: «Las quiebras del orden cotidiano: comportamientos criminales en la sociedad gallega de fines del Antiguo Régimen», Obradoiro de Historia Moderna, 13, 2004, pp. 277-302.

8. Las fuentes eclesiásticas en las que se basa esta investigación se tratan de los pleitos por Secuestro recogidos en el Archivo Diocesano de Zaragoza [en adelante ADZ] que cuenta con un importante fondo de alrededor de 454 pleitos de secuestro de bienes, esposas y doncellas. Los pleitos por esponsales y estupro llevados en este tribunal, así como en los Diocesanos de Huesca, Barbastro y Teruel indican también la utilización de este recurso, aunque no siempre contemos con el registro notarial. De forma complementaria, la presente investigación hace también referencia a pleitos por jactancia o estupro ubicados también en el Archivo Diocesano de Zaragoza.

9. Diccionario de Autoridades, Tomo VI, 1739.

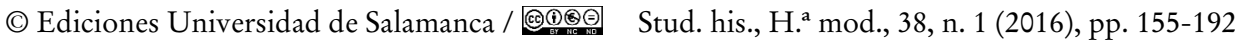


elemento de disputa, en estos casos la mujer y se disponía un tribunal que decidiese bajo qué autoridad debía ser ubicado. La única referencia específica al respecto en el derecho canónico se encuentra en una intersección entre el Decreto de Graciano sobre la promesa de esponsales y el Matrimonium initiatum ${ }^{10}$ y de la acepción «De las acciones y excepciones» que especificaba lo siguiente:

Aquel que hace ver al menos con argumentos probables que tiene derecho sobre una cosa que está en poder de otro, y que puede ocasionársele un daño si no se pone bajo custodia, tiene derecho a obtener del juez el secuestro de la misma cosa ${ }^{11}$.

Es importante distinguir el proceso de secuestro del rapto. El rapto de doncellas estaba penado dentro y fuera de Aragón. Las ordinaciones y cartas pueblas hacían referencia a las raptadas como extraídas contra su voluntad, esto podía ser o no cierto pero se basaba en que el acto era ilegal ${ }^{12}$. Los padres que reclamaban la manifestación de sus hijas solían declarar que habían sido raptadas o al menos engañadas. Salvo en estos casos, el argumento predominante era que existía compromiso entre la pareja y, por tanto, lo legal era ratificar su matrimonio ${ }^{13}$.

El proceso de secuestro era señalado en el Diccionario de Autoridades como un recurso «poco utilizado». Los datos recogidos en la diócesis de Zaragoza indican no obstante que fue un recurso habitual a finales del Antiguo Régimen. Estas extracciones se realizaban a petición de las muchachas o en casos especiales de sus prometidos. En 1800, Las Instituciones del derecho público general de España con noticia particular de Cataluña hacían especial referencia al «secuestro o depósito de las doncellas». Las Reales Cedulas del 17 de junio de1784 y del 1 de febrero de 1785 establecían que los jueces eclesiásticos no podían consentir las extracciones, y depósitos de las hijas de familia, sin noticia y consentimiento de sus padres, y tutores. Por otra parte, las reales cédulas del 23 de octubre de 1785 y del 18 de septiembre de 1788 especificaban que «los depósitos de las hijas de familias, que se hacen por opresión, y para explorar la libertad, se expidan por

10. Corpus Iuris Canonici. Decretum Gratiani, Concordia discordantum canonum, Corpus Iuris Canonici, post c, 34, 1140-1142.

11. Ibidem. Libro VII, II, 1496, $₫ 1$.

12. Laliena Corbera, C.: «Honor, vergüenza y estatus en las familias serviles del Pirineo Central en la Edad Media», en Iglesia Duarte, J. I. de la (coord.): La familia en la edad media: XI Semana de Estudios Medievales, Nájera, del 31 de julio al 4 de agosto de 2000. Instituto de Estudios Riojanos, 2001, pp. 179-208.

13. Aunque los esponsales solo eran legalmente válidos ante un tribunal eclesiástico, ningún tribunal podía aceptar un matrimonio totalmente forzado. Torremocha Hernández, M.: «El matrimonio y la relación de los cónyuges en la Castilla postridentina (en la literatura de la época)», en Bestard, J. y Pérez, M.: Familia, valores y representaciones. Murcia, 2010, pp. 155-178.

(C) Ediciones Universidad de Salamanca / ®@ Stud. his., H. ${ }^{a}$ mod., 38, n. 1 (2016), pp. 155-192 
el juez» ${ }^{14}$. La regulación de estos procesos estaba directamente vinculada a los tribunales diocesanos independientes del poder real. Existen muy pocos estudios sobre la presencia de procesos de secuestro en los tribunales diocesanos, muchos de ellos en un contexto más amplio de análisis de la actividad legal de los mismos ${ }^{15}$.

La frecuencia y el relativamente bajo coste del procedimiento convirtió el proceso de secuestro en una potente herramienta de libertad para los jóvenes comprometidos. En el lado opuesto, el proceso de manifestación se originaba en el código foral aragonés, que en el siglo XviII era administrado desde los corregimientos y la Audiencia. La visión del matrimonio como un proceso mucho más vinculado a la autoridad familiar que a la libertad condujo a que las manifestaciones, con un planteamiento legal similar a los secuestros, funcionasen mejor como instrumentos para hacer prevalecer las estrategias familiares sobre la voluntad de los hijos. De los 136 casos de manifestación analizados, la gran mayoría eran de disputas entre padres e hijos y muchos se saldaban con la devolución de los manifestados a la casa de sus padres.

\begin{tabular}{|l|c|}
\hline Manifestaciones según sus objetivos & Casos \\
\hline Manifestación (reclamación) de esposa & 5 \\
\hline Manifestación (reclamación) de marido & 1 \\
\hline Manifestación (reclamación) de prometido & 9 \\
\hline Manifestación (reclamación) de un hijo o tutelado & 36 \\
\hline Manifestación de la propia persona contra su familia & 30 \\
\hline Manifestación de la propia persona contra la autoridad legal & 18 \\
\hline Manifestación de bienes muebles o propiedades requisadas & 37 \\
\hline
\end{tabular}

Figura 3: tipología de los procesos de manifestación según su objetivo ${ }^{16}$.

14. Dou y De Bassols, R. L. de: Instituciones del derecho público general de España con noticia particular de Cataluña, y de las principales reglas de gobierno en qualquier estado. Madrid, 18001803, pp. 238-239. Indicado en CostA, M.: «La problemática de las promesas de matrimonio en Barcelona 1776-1833», Pedralbes, 28, 2008, pp. 553-584.

15. Entre los más destacables es preciso mencionar a Costa, M.: Conflictos matrimoniales $y$ divorcio en Cataluña: 1775-1833. Tesis doctoral presentada en la Universitat Pompeu i Fabra. Barcelona, 2007, pp. 54-85. CANDAu CHAcón, M. L.: Los delitos y las penas en el mundo eclesiástico sevillano del XVIII. Sevilla, Diputación Provincial de Sevilla, 1993, pp. 165-180. Más específicamente sobre la retención femenina por parte de las instituciones véase GHIRARDI, M.: «El encierro femenino como práctica. Notas para el ejemplo de Córdoba, Argentina, en el contexto de Iberoamérica de los siglos XVIII y XIX», Revista de Historia Social y de las Mentalidades, 14:2, 2010, pp. 73-101.

16. El fondo documental de manifestaciones analizado consta con 136 pleitos de manifestación para el siglo XVIII conservados en el Archivo Provincial de Zaragoza [en adelante APZ] donde se

(C) Ediciones Universidad de Salamanca / ®@ Stud. his., H. ${ }^{a}$ mod., 38, n. 1 (2016), pp. 155-192 
Los únicos procesos de manifestación en los que las doncellas eran extraídas de la autoridad de sus padres por haberles impedido su matrimonio son los definidos como «Manifestación de la propia persona contra su familia». En comparación con el proceso de secuestro, se trataba de un recurso mucho menos utilizado por los hijos. La manifestación dependía de la Audiencia, es decir que no se basaba en el concepto de libre albedrío para determinar la formación de matrimonios. Los distintos principios jurídicos con los que cada autoridad interpretaba el concepto de familia y de sociedad podían cambiar radicalmente el resultado de las acciones judiciales ${ }^{17}$.

El proceso de manifestación por su parte era llevado desde los Decretos de Nueva Planta por la Audiencia de Zaragoza, podía funcionar de una forma similar al secuestro y obtener los mismos resultados ${ }^{18}$. El papel más importante y conocido del proceso de manifestación aragonés había sido el de proteger a reos aragoneses de detenciones arbitrarias o juicios que no respetasen las garantías forales ${ }^{19}$. Tras 1707, la potestad de ejercer la manifestación pasó a las instituciones reales y lógicamente su funcionamiento se reorientó a actuar contra las autoridades exentas del poder real. El respeto a las libertades forales seguía siendo importante en Aragón, pues Felipe V había mantenido intacto el código civil. En virtud a este privilegio, los regnícolas podían reclamar manifestación ante la sospecha de que se estaban violando sus derechos enunciándolo de la siguiente forma:

Que mi parte se encuentra en poder de personas privadas que la oprimen y hacen violencia en su persona y en todas sus acciones y a fin de estar en la libertad que por fuero del presente reino le es debida. Por tanto a Vuestra Merced pido y suplico provéanla el presente apellido de manifestación y en su virtud se sirva mandar que, por los ministros a quien toca, se haga de manifiesto la persona de mi parte y manifestada en poder y manos de vuestra merced se mande en todo lo prevenido por fuero ${ }^{20}$.

ubican los registros de los procesos llevados por la Audiencia de Zaragoza No obstante, solo 99 manifestaciones se dirigieron a dirimir la custodia de personas.

17. Se puede observar la importante diferencia entre los procesos llevados por distintos tribunales en los estudios realizados por Juncal Campo Guinea, M.: «La actividad procesal de los tribunales de justicia en Navarra en el estudio de cambios y permanencias (siglos XVI-XIX)», Cuadernos de investigación histórica, 18, 2001, pp. 87-100 y en «Los procesos por causa matrimonial ante el tribunal eclesiástico de Pamplona en los siglos Xvi y Xviı, Príncipe de Viana, 202, 1994, pp. 377-390.

18. Sobre la restauración del proceso foral véase LARRIPA, J. F.: Ilustración a los cuatro procesos forales de Aragón. Edición de Bonet Navarro, Á. y Redondo Veintemillas, G., Zaragoza, Cortes de Aragón, 1985.

19. Morales Arrizabalaga, J.: «El justicia de Aragón en el siglo XviII: la transición de una institución jurisdiccional a un símbolo político», en Actas del Octavo encuentro de estudios sobre el Justicia de Aragón. Zaragoza, 2008, pp. 45-78.

20. Archivo Histórico Provincial de Zaragoza, Archivo de la Audiencia, Manifestación, 1749, $12319-9$.

(C) Ediciones Universidad de Salamanca / ®@ Stud. his., H. ${ }^{a}$ mod., 38, n. 1 (2016), pp. 155-192 
En lo que respecta a su evolución. Los procesos de secuestro y manifestación siguieron a grandes rasgos la misma evolución que el resto de pleitos familiares dirimidos en el mismo espacio geográfico o en regiones similares: la conflictividad familiar experimentó un ascenso a lo largo del siglo.

Evolución de los casos de secuestro

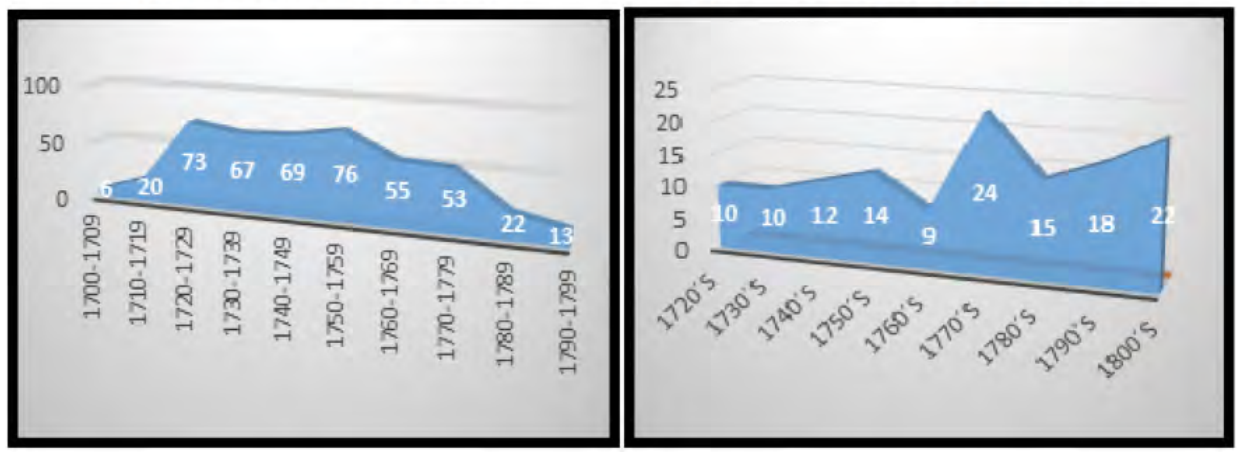

FiguRA 4: evolución de los pleitos por secuestro en el tribunal diocesano de Zaragoza en el siglo XVIII ${ }^{21}$.

La creciente conflictividad social provocada por cuestiones matrimoniales quedó reflejada en los procesos judiciales; pero también en otras fuentes como el teatro neoclásico, la prensa de la época y muy especialmente las quejas de los moralistas que hablaban de la relajación de las costumbres que regían la formación de matrimonios y el comportamiento de las mujeres ${ }^{22}$. Como los alarmados autores advertían, el siglo xviII presenció un incremento de estos procesos de secuestro y manifestación en los que se enfrentaban padres contra hijos o se reclamaba matrimonio a quien los había prometido para después desaparecer ${ }^{23}$. Del mismo modo, el siglo xviII también se caracterizó por un incremento de las nociones de

21. ADZ, Secuestros (1700-1800), indexación realizada por el autor. APZ, manifestaciones (1720-1810), indexación y análisis realizado por el autor. Elaboración propia.

22. Martín Gaite, C.: Usos amorosos del XViII en España. Barcelona, 1988, pp. 150-154. Bolufer Peruga, M.: «Mujeres y hombres en el espacio del reformismo ilustrado: debates y estrategias», en Jornada Mujer i ciudadania: del Antiguo Régimen a la Revolución liberal. Departament Història Moderna i Contemporània, Instituto de la Mujer, 2003 en https://www.academia.edu/5525810/ Mujeres_y_hombres_en_los_espacios_del_reformismo_ilustrado (última consulta: 27/01/2015).

23. Análisis desarrollado mediante los Procesos de Manifestación desarrollados en la Audiencia de Zaragoza (1726-1820), ubicados actualmente en el Archivo Provincial de Zaragoza.

(C) Ediciones Universidad de Salamanca / ®@ Stud. his., H. ${ }^{a}$ mod., 38, n. 1 (2016), pp. 155-192 
individualismo que condujeron a que las parejas se rebelasen con mayor frecuencia a las estrategias matrimoniales impuestas.

La cantidad de pleitos por manifestación que acogió la Audiencia de Zaragoza sobre conflictos entre padres e hijos fue notablemente inferior a los que fueron recogidos por motivos similares en el tribunal de la Archidiócesis de Zaragoza. Hay que hacer al respecto dos apreciaciones sobre la importancia de la manifestación. En primer lugar, era un proceso que podía iniciarse en cada localidad aragonesa bajo la autoridad del alcalde o del corregidor, por lo que a día de hoy resulta imposible conocer la importancia real de este recurso. En segundo lugar, abundante o no, este proceso había dejado una profunda huella en la cultura aragonesa, pues la mayoría de los casos de secuestro de doncella o extracción de una esposa de su hogar eran denominados por testigos y litigantes «manifestación», independientemente de la autoridad de la que dependiesen.

\section{SeCUESTRo y MANIFESTACión EN EL CONTEXTO DE LA CONFLICTIVIDAD FAMILIAR}

Frente a la visión tradicional de la sociedad del Antiguo Régimen como un mundo estático, la conflictividad que podía generar en la comunidad algo tan cotidiano como un matrimonio refleja una situación no de ruptura pero sí de tensión entre intereses en las que cada parte tendría que ceder posiciones ${ }^{24}$. El secuestro y la manifestación constituían elementos de poder para reclamar la autoridad sobre un familiar o sobre uno mismo, pero siempre de acuerdo a unos principios socialmente aceptables. Posiciones en principio muy fiables como la autoridad paterna para con los hijos quedaban atenuadas ante las acciones de secuestro que se justificaban con la arraigada acción de «raptar de la novia» ${ }^{25}$. El secuestro amparaba este tipo de actuaciones siempre que fuesen conducidas por los representantes de la diócesis. De hecho, es probable que este proceso se estableciese como una forma de regularizar los raptos tradicionales. Para valorar la importancia de esta justificación moral, veamos en primer lugar qué ocurría cuando en lugar de recurrir a un secuestro oficial, la pareja optaba por soluciones algo menos ortodoxas.

En la primavera de 1773, los habitantes de la población aragonesa de Cutanda presenciaron una crisis familiar que no por conocida resultó menos escandalosa.

24. Bonfield, Ll:: «Avances en la legislación familiar europea», en Kertzer, D. y BARBAGLI, M. (Comp.): La vida familiar a principios de la era moderna (1500-1789), Historia de la familia europea. Volumen I. Barcelona, 2002, pp. 153-204.

25. Las investigaciones sobre las prácticas de cortejo en Europa han señalado numerosos ritos equiparables al rapto ritual de las mujeres como una forma en la que los varones reclamaban su autoridad sobre sus futuras esposas: SHORTER, E.: The Making of Modern Family. Londres, 1977, pp. 120-135.

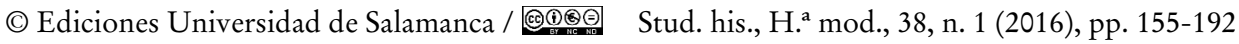


Un joven y bien posicionado labrador llamado Pedro Lázaro había estado cortejando a una muchacha perteneciente a un honrado linaje del lugar. Esta familia, los Valero de Liria, eran una de las más antiguas casas de Cutanda y ostentaban el título de hidalguía. Por su parte, la familia de Pedro Lázaro era reconocida como «de labradores honrados», es decir: vecinos respetables pero no hijosdalgo. Debido a estas circunstancias, Don José Valero de Liria había prohibido expresamente a su hija Josefa aceptar el «trato y comunicación» que Pedro Lázaro la ofrecía ${ }^{26}$. La diferencia de estatus social era considerada en principio un impedimento dirimente para contraer matrimonio, lo que daría la razón al padre. Esta situación podría no haber ido más allá de no ser porque, aquella mañana en cuestión, Don José descubrió que su hija había desaparecido de su cuarto y con ella casi la totalidad de sus muebles y ropas que debían formar parte del ajuar de la misma. No era difícil imaginar qué había ocurrido y quiénes estaban implicados. Por desgracia para el hidalgo, él no sería el único cutandino que conjeturaría al respecto ${ }^{27}$. La discreción con la que se había llevado a cabo la salida de la muchacha sugería que esta había huido voluntariamente. No obstante, José Valero no dudó en denunciar que su hija había sido sacada contra su voluntad por el varón que la había estado rondando.

Aunque Valero de Liria movilizó al obispado y el corregimiento, no fueron sus hombres quienes trajeron noticias de su hija a la familia, sino el propio párroco de Cutanda que se confesó cómplice del secuestro. De acuerdo con su propia declaración, este sacerdote y reconocido casamentero había ejercido como mediador entre la pareja y sabía qué había sido de los jóvenes. Utilizando al sacerdote como intermediario, el novio y raptor Pedro Lázaro hizo saber al tribunal la ubicación de la muchacha y sus razones para raptarla:

Que teniendo firme palabra de matrimonio dada con la dicha Josepha Valero que se hallaba impedida en casa de sus padres (...) y pasada la media noche, poco más o menos. Para su extracción solo se halló el contrayente; que estuvo en el corral de la casa hasta que ella abrió el ventano y sacó algún tanto de mueble; y después cargaron ambos lo movible y se fueron solos mano a mano hasta un río que hay fuera de este lugar en donde se reunieron con un hermano del contrayente (...) Y

26. La expresión «trato y comunicación» es la expresión común que hacía referencia al cortejo formal que se esperaba que una pareja siguiese con el objetivo de darse a conocer entre ellos y a sus respectivas familias.

27. El cotilleo constituía en las sociedades del Antiguo Régimen una importante herramienta de construcción del tejido de la comunidad con una doble función: marcar los límites de los subgrupos y activar la competencia para defender la comunidad propia. Imizcoz Benza, J. M.: «Familia y redes sociales en la España Moderna», en Lorenzo Pinar, F. J. (ed.): La familia en la Historia. Salamanca, 2008, pp. 135-186.

(C) Ediciones Universidad de Salamanca / @@@ Stud. his., H. ${ }^{a}$ mod., 38, n. 1 (2016), pp. 155-192 
luego caminaron para el lugar de Collados, solos los tres (...) y habiéndose llegado a dicho pueblo la llevaron a casa del Alcalde sin preceder testigos ni persona alguna de autoridad que solemnizase el acto ${ }^{28}$.

Aquella misma noche, Josefa Valero quedó bajo la vigilancia de la esposa del alcalde de Collados. La doncella también se apresuró a declarar en un intento de apaciguar a sus padres que «su ánimo ha sido y es con intención de contraer matrimonio con Pedro Lázaro, que no hubo violencia ni engaño sino nacido todo de su plena y espontanea voluntad $»^{29}$. Posteriores declaraciones de Josefa Valero ratificaban que ella había aceptado el rapto e incluso que lo había promovido. La doncella había rechazado los planes que su padre había preparado para ella y en vista de su insistencia, Josefa se aseguró de ser secuestrada. Como mujer, no podía secuestrarse a sí misma, pero fue su intervención lo que permitió el éxito del proyecto ${ }^{30}$.

La espontanea voluntad de la pareja no era suficiente como para justificar una fuga del hogar. Ambos defendían que no habían hecho nada inmoral: eran jóvenes adultos, en edad adecuada para el matrimonio, tenían el beneplácito de su párroco y la obstrucción puesta por el padre de ella era, según su punto de vista, injustificada. Es cierto que en estas circunstancias, el secuestro de la doncella era una opción válida; el error fue realizarlo sin la debida autorización del tribunal y aún peor: con nocturnidad y alevosía.

El caso expuesto se trataba de un hecho cotidiano y a la vez excepcional. La reclamación que hacían los jóvenes de Cutanda, por más que ilegal, era moralmente aceptable: Josefa Valero denunciaba que su padre ejercía sobre ella una autoridad que había desaparecido en el momento en el que ella se había prometido a su futuro marido. La moral popular daba por sentado que un padre no solo podía, sino que debía controlar los planes matrimoniales de sus hijos; pero negar un matrimonio aceptable a una doncella con la edad adecuada y un pretendiente aceptable resultaba lo bastante transgresor como para que el tribunal eclesiástico o la Audiencia decidiera actuar. Ante una demanda, la autoridad en cuestión procedía a retirar a la muchacha de la autoridad familiar para determinar en primer lugar si era libre

28. Secuestros, ADZ, 1773, Caja sin catalogar, $\mathrm{n}^{\circ} 1$.

29. Ibidem.

30. Las investigaciones sobre las mujeres del Antiguo Régimen ha demostrado que su papel real en la vida cotidiana era mucho más relevante de lo que la literatura institucional reconocía. Véase: Rey Castelao, O.: «Mujeres en la economía campesina», en Morant, I. (coord.): Historia de las mujeres en España y América Latina, vol. 2. Barcelona, 2005, pp. 263-286. PAscuA Sánchez, M. J. de la: «Una aproximación a la historia de la familia como espacio de afectos y desafectos en el mundo hispánico del setecientos», Chronica nova: Revista de historia moderna de la Universidad de Granada, 27, 2000, pp. 131-166.

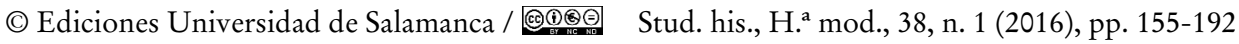


de ejercer su voluntad; $y$ en caso de serlo, que declarase sin presiones y en lugar seguro cuál era dicha voluntad.

Para comprender este concepto aplicado a la libertad de matrimonio, pongamos por ejemplo una guía moral sobre cómo actuar en estos casos. El manual para confesores publicado en 1706 por Fray Francisco Larraga exponía firmemente la importancia de obedecer a los padres y tutores por el bien del alma y de la comunidad: «Si queriéndose casar, no se casa con quién quiere el padre que con más maduro consejo y experiencia conoce las cosas $»^{31}$. Sin embargo, el propio sacerdote matiza esta regla cuando las órdenes paternas fuesen contra la moralidad de la iglesia, especialmente en cuestiones de matrimonio. Según estas nociones morales:

(...) se ha de considerar si hay o no justa causa para dejar de obedecer al padre, porque si la mujer que quiere dar el padre al hijo aunque sea rica es de familia desigual o inferior o es enferma, fea, fatua o vieja no peca el hijo no obedeciendo al padre ${ }^{32}$.

En cuestión a las reglas expuestas por el Padre Larraga: no sabemos si Josefa Valero era fea o una beldad. Lo que es seguro, es que no mediaba parentesco entre ella y su pretendiente, la edad de ambos era similar y nadie les había obligado a prometerse. Por otra parte, mediaba una cierta desigualdad en su posición social tal y como tuvo que reconocer el mismo párroco que les animó a realizar el secuestro de forma ilegal:

En cuanto a lo expuesto en el memorial de la disparidad, debo decir a usted que sin quietar nada en su línea, al honor de facultativos del contrayente y su padre, es cierto e innegable no llegar al realce y lauro de los Valeros de Liria, por hallarse en su día emparentados y enlazados con las más distinguidas familias de las comunidades de Teruel y Daroca, cuyos antecesores han obtenido los honoríficos puestos y empleos, de recetores y diputados con los que han gobernado ambas comunidades y siempre han conservado aquel lustre que les compete por su sangre ${ }^{33}$.

Aunque en el pleito no se llegó a especificar, la desigualdad podría ser la razón por la que Pedro Lázaro optó por el secuestro ilegal en lugar de recurrir a los tribunales eclesiásticos o a la Audiencia de Zaragoza. En este caso, el honrado don Valero de Liria tenía autoridad para reclamar la devolución de su hija.

En contraste con este extraño caso, la mayoría de los procesos recogidos en la Audiencia de Zaragoza y los tribunales eclesiásticos sugieren que cuando

31. Morgado García, A.: «Los manuales de confesores en la España del siglo XviII», Cuadernos Dieciochistas, 5, 2004, pp. 123-145.

32. Ibidem.

33. Secuestros, ADZ, 1773, Caja sin catalogar, 1.

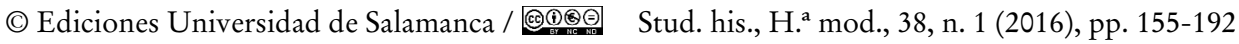


DANIEL BALDELLOU

TRANSGRESIÓN Y LEGALIDAD EN EL CORTEJO DEL SIGLO XVIII:

EL SECUESTRO DE MUJERES EN LA DIÓCESIS DE ZARAGOZA

había pruebas evidentes de fuerza, los procesos legales de secuestro e incluso el de manifestación funcionaban con efectividad como resortes legales para extraer a una mujer del lugar donde su libertad personal estuviese siendo coartada. Había muchas razones por las que el descarriado secuestro que ejecutó Pedro Lázaro merecía como mínimo la reprobación de la comunidad; pero sin duda la principal era que, en lugar de recurrir a un notario cualificado, él había tomado parte activa en la extracción de la doncella.

\section{Secuestro bueno, secuestro malo: una cuestión de recato}

El caso de Josefa Valero constituye una excepcionalidad en los procesos por secuestro, se parece más a los casos en los que los padres recurrían a la manifestación para hacer que sus hijos volviesen a casa. Los procesos de secuestros o manifestación tenían que ser enunciados como un acto de agresión contra la libertad del individuo a secuestrar, ya fuese contra su libre albedrío o sus derechos forales. La retención forzosa era un acto muy subjetivo. El libro del padre Larraga era un manual para confesores, los libros dirigidos a educar a la moral popular eran mucho más estrictos en cuanto a la autoridad paterna, dando por hecho que obedecer a los padres era lo virtuoso a priori. Un principio que se aplicaba tanto en los manuales didácticos como en el teatro e incluso la escritura satírica ${ }^{34}$.

Una razón de peso para inmiscuirse en la autoridad paterna era imprescindible para este tipo de actos se considerasen justificables. No se trataba solamente de una cuestión legal. Por supuesto, las autoridades judiciales no actuarían sin la sospecha de un acto contra su ley de referencia, pero también era necesario que la transgresión fuese evidente a ojos de la comunidad. La intervención de funcionarios eclesiásticos o del reino era una forma de demostrar que la salida del hogar familiar se debía a una razón legítima, pero en ocasiones esto no bastaba para satisfacer los rumores de la comunidad ${ }^{35}$. Los testimonios favorables de parte de una autoridad local como el párroco eran una forma de asegurar la justificación del secuestro. Incluso en casos como el de Cutanda en el que la extracción de la novia se había llevado a cabo sin la mediación de las autoridades. Finalmente, en situaciones muy graves en las que los escándalos familiares habían trascendido

34. García Martínez, M. I.: Álvarez Faedo, M. J. y Simón-Schuhmacher, L.: La educación de la mujer en el siglo XVIII en España e Inglaterra. Lewiston, 2005, pp. 93-98 y pp. 120-129.

35. Las redes de comunicación populares o sencillamente el cotilleo eran una forma eficaz de controlar las acciones contrarias al orden de la comunidad. Convencer a los vecinos de que las extracciones del hogar se debían a razones de peso era esencial para ser aceptados posteriormente. O'HARA, D.: Courtship and Constraint. Rethinking the Making of Marriage in Tudor England. Manchester, 2002, pp. 41-48.

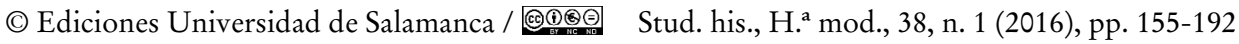


de la esfera privada, los papeles se invertían y tanto vecinos como autoridades apoyaban la extracción legal de las hijas o las mujeres antes de que las actitudes violentas de sus familias terminasen en una desgracia. Esta situación era muy frecuente en los casos en los que una mujer casada solicitaba ser extraída de su hogar por riesgo a que las acciones de su marido terminasen por costarle la vida. Toda la comunidad solía estar al tanto del riesgo que suponía un matrimonio conflictivo, por lo que no era difícil encontrar testigos que apoyasen su versión como en el siguiente caso ocurrido en Zaragoza:

Hará cinco meses poco más o menos que la dicha Manuela Vubia contrajo su segundo matrimonio con el dicho José Casanova y han sido marido y mujer (...). Debe saber sin embargo que el dicho José Casanova llevado de su mal genio, después de haber contraído dicho matrimonio ha maltratado e injuriado a la dicha de obras y palabras tratándola con palabras indecentes que expresan los testigos en desdecoro de su estimación y reputación y aun cogiendo espada contra la susodicha y echándole amenazas de manera que ha estado y está muy a riesgo de la vida de Manuela ${ }^{36}$.

En otras ocasiones, eran los padres y no los maridos los que actuaban con violencia. Los resultados eran prácticamente los mismos: si el escándalo llegaba a manos del tribunal, era fácil que aprobasen un secuestro preventivo hasta determinar si se trataba realmente de un acto de fuerza. El caso más extremo fue el de Joaquina Genzor, una doncella noble de Celsa que se había comprometido con Matías Salvatierra, boticario de Zaragoza. Dada la diferencia estamental entre la pareja, el padre de Joaquina reaccionó con violencia al saber que la pareja se había comprometido. Matías se había desplazado a Zaragoza para solicitar el secuestro donde, a modo de prueba, presentó al tribunal una carta enviada por su padre relatando los últimos acontecimientos de Celsa:

Hijo mío, (...) ¡Que terremotos en casa de Valentín con que sobre haberle encontrado a Joaquina el paquete que tendía enfardetado! ¡Qué castigos tan inhumanos que ponerle al pecho de punta una espada y una pistola y levantadas las greñas para matarla! ¡Qué voces la pobrecita daba pidiendo favor al cielo y a su madrastra y el con voces descompasadas! (...) A toque de misa mayor oímos tu madre y yo como lloraba y que pudo Felix Almozín (el alcalde de Celsa) quitarle la acción, pues fue avisado para eso (...) y aún la pobrecita a todo esto se mantuvo firme, sin querer declararle nada a su padre teniéndola encerrada en una alcobita que tiene en la sala ${ }^{37}$.

La veracidad de los hechos relatados en la carta por José Salvatierra fue certificada posteriormente por el párroco y el alcalde de la localidad. El tribunal

36. ADZ, Secuestros, 1743, B-H LIG 23.

37. ADZ, Secuestros, 1771, Lig. 1, J y otros.

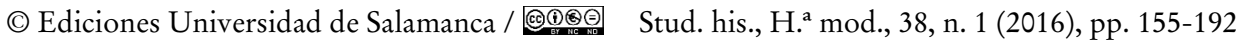


diocesano no esperó a obtener la confirmación y ordenó el secuestro preventivo de Joaquina Genzor. El caso expuesto por Matías Salvatierra corresponde a grandes rasgos a las situaciones descritas en la mayoría de los procesos de secuestro. Las protagonistas eran en todos los casos mujeres solteras comprometidas con un varón al que sus familias no aprobaban. No se daban casos de varones extraídos de sus hogares mediante una autoridad ajena si no era para encausarlos por un delito.

Existen algunos casos minoritarios de manifestación en los que se extraía a varones solteros de sus casas para obligarles a cumplir sus promesas de matrimonio o evitar que las cumpliesen. Lo normal de todos modos era que fuesen las mujeres las que lo solicitasen. No existe una razón legal específica para esta discriminación. Probablemente se deba a que se consideraba a los varones mucho más independientes que las mujeres para elegir a la esposa adecuada. La literatura moral dieciochesca seguía considerando a las mujeres menos capacitadas que los hombres para escoger a un marido adecuado ${ }^{38}$. En realidad, esta acepción no era totalmente cierta a juzgar por los casos en los que constan muy efectivas presiones de los padres sobre sus hijos para que aceptasen contraer matrimonio de acuerdo a sus estrategias familiares ${ }^{39}$. Es también probable que fuese considerado una vergüenza por parte de los hombres tener que recurrir a una autoridad ajena para enfrentarse con sus padres.

El siglo XviII comenzó a dar señales de un ascenso del individualismo en detrimento de la organización familiar. La organización tradicional de las familias estaba lejos de desaparecer, sin embargo varios autores han ratificado que los deseos personales o el sentimiento amoroso comenzaron a crecer como razón legítima para contraer matrimonio, así como la apreciación de las mujeres como sujeto público ${ }^{40}$. La Ilustración presenció la siembra del cambio social que se manifestó plenamente décadas o incluso siglos más tarde; en lo que al xviII se refiere, la formación de matrimonios siguió siendo un asunto estrictamente familiar en el que las familias solo cedían la autoridad sobre sus hijas tras evaluar al pretendiente. El acto en el que se iniciaba de forma efectiva esta cesión de la autoridad del padre al futuro marido era el acto de esponsales, un proceso que no preveía en ningún

38. Sobre las apreciaciones ilustradas sobre la incapacidad de las mujeres para desenvolverse por sí mismas véase Morant Deusa, I. y Bolufer Peruga, M.: «Sobre la razón, la educación y el amor de las mujeres: mujeres y hombres en la España y en la Francia de las luces», Studia Historica. Historia Moderna, 15, 1996, pp. 179-208.

39. Baldellou Monclús, D.: «El honor de los padres y la libertad de los hijos: la aplicación del veto paterno a los matrimonios transgresores en la España preliberal», en Alfaro Pérez, F. (coord.): Familias rotas. Conflictividad familiar a finales del Antigno Régimen. Zaragoza, 2014, pp. 55-104.

40. Bolufer Peruga, M.: «Lo íntimo, lo doméstico y lo público: representaciones sociales y estilos de vida en la España Ilustrada», Studia Historica. Historia Moderna, 19, 1998, pp. 85-116.

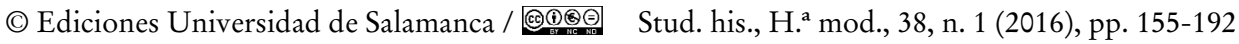


momento la emancipación de la hija, pues esta pasaba de una autoridad a otra. El rapto de la novia o peor aún su fuga del hogar familiar suponía una transgresión al permitir que esta actuase sin supervisión.

El secuestro y la manifestación se trataban de una solución intermedia. Asumiendo la necesidad de una remoción, los tribunales buscaban garantizar las libertades de los regnícolas minimizando los daños contra la jerarquía social establecida. Perder la autoridad sobre una hija o una esposa no era gratificante, pero si se hacía en favor de una autoridad superior el daño a la honra familiar era mucho menor. Las escasas denuncias por raptos ilegales o fugas del hogar como la de Josefa Valero sugiere que el secuestro regularizado por el tribunal eclesiástico se trataba de un proceso habitual y conocido por la comunidad. Existen algunos registros menores sobre procesos de secuestro y manifestación de mujeres solteras en los siglos XVI y XVII, no obstante su volumen es mucho menor. Es probable que los registros de siglos anteriores estén incompletos, no obstante se puede observar un importante incremento de este recurso desde finales del siglo xvir para alcanzar su zenit a mediados del siglo xviII, cuando la autoridad real comenzó a reaccionar en favor de la autoridad paterna.

La opinión popular era favorable al ejercicio de la Patria Potestas. A cambio, se daba por sentado que los padres se esforzarían en casar adecuadamente a sus hijos. Sin embargo los padres, como bien sabían los expertos, no siempre buscaban el bien de sus hijos. En ocasiones, las familias establecían matrimonios pensando más en las alianzas y las ventajas económicas frente al deseo de sus descendientes. Como se reconoció en la Real Pragmática de 1776, los familiares podían forzar un matrimonio inadecuado pensando solo en sus intereses particulares: «Y así contra el irracional disenso de los padres, abuelos, parientes, tutores o curadores, en los casos (...) debe haber y admitirse libremente recurso sumario a la Justicia Real Ordinaria» ${ }^{41}$.

Para evitar que los padres cometiesen una injusticia y partiendo de que este acto siempre resultaría escandaloso, el proceso legal de secuestro buscaba realizar una mediación de la forma menos transgresora posible. No se trataba simplemente de una remoción para poner en libertad a alguien, sino de una custodia temporal hasta que el tribunal decidía bajo qué autoridad debía ubicarse el secuestrado. El objetivo final era que el secuestro llevado a cabo por el tribunal eclesiástico tuviese el mismo efecto que el ritual socialmente aceptable de «rapto de la novia».

Los pleitos de secuestro y manifestación tenían que empezar necesariamente con una denuncia. La mayor parte de los procesos de remoción de mujer soltera para contraer matrimonio eran las propias mujeres las que reclamaban ser extraídas

41. Real Pragmática Sanción de 1776, Novísima Recopilación, Título II, Ley IX.

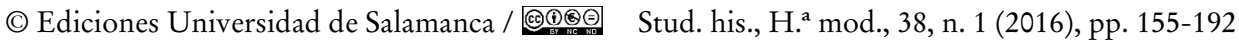


de su hogar. Su reclamación hacía constar que se encontraban «oprimidas y sin poder ejercer su natural libertad». Que las denunciantes pudiesen personare ante el tribunal o incluso que pudiesen contar con la presencia de un abogado causídico indica que su opresión era más simbólica que efectiva. La autoridad paterna era un principio a respetar pasase lo que pasase. En la mayoría de los casos, bastaba la prohibición verbal de un matrimonio para que una mujer necesitase la intervención de la autoridad judicial. Aunque no la tuviesen físicamente retenida, cualquier otra alternativa como huir de la casa sería arriesgar su reputación y la de su familia.

El formato de la denuncia presentada para obtener la remoción del hogar familiar variaba según el caso. El común denominador de secuestros y manifestaciones de mujeres solteras era expresar la existencia de dos elementos: un abuso de autoridad sobre las mujeres realizado por sus familias y la existencia de una promesa matrimonial que inhabilitaba la autoridad del padre como en el siguiente ejemplo.

Que tengo dada palabra y promesa a Yldefonso Bagués del lugar de Leciñena, (...), pero mi padre y parientes torciendo mi voluntad lo han de embarazar y estorbar por cuantos caminos y modos les sea posible y quieren que no contraiga matrimonio (...) ratifico mediante este instrumento de poder y dándole fuerza de esponsales (que) quiero ser mujer y esposa legítima de dicho Yldefonso Bagués de modo que de mi buen grado y cierta ciencia, no seducida ni engañada, es de mi espontanea voluntad les constituyo y nombro en procuradores míos legítimos a todos juntos. (... ) Y que pidan (al arzobispado) con la calidad sobredicha (que) me secuestre y secuestrada y se me lleve a la parte y puesto donde yo pueda libremente explicar mi voluntad y efectuar dicho matrimonio ${ }^{42}$.

Como puede observarse, no era necesario alegar peligro de muerte o encierro físico. Hacer constar que la mujer estaba comprometida y que sus familiares estaban obstruyendo el enlace era suficiente. Lo expuesto arriba es un caso ejemplar de cómo lograr el beneplácito de la autoridad eclesiástica. La clave para comprender este resorte está en la concepción del género femenino. Era impensable extraer a una mujer del hogar sin que contase con un plan de futuro en firme que justificase su salida o dicho de otro modo: no se podía dejar de ser hija si no era para empezar a ser esposa. Al reconocer su compromiso de esponsales, la denunciante Joaquina Sieso hacía constar que en el momento que dio su palabra de matrimonio había pasado a estar bajo la autoridad de su marido y que su padre no tenía derecho a retenerla en el hogar sin una razón de peso.

La única razón de peso factible era que el matrimonio proyectado por la pareja no fuese válido de alguna forma y por lo tanto la doncella siguiese bajo la autoridad

42. ADZ, 1759, Secuestros, J Lig. 2.

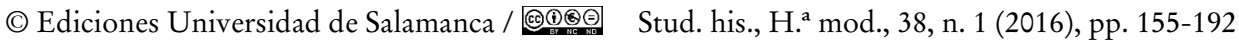


de su padre. La mayor parte de los secuestros no recogen una oposición clara por parte de los padres. Solo en los casos en los que el secuestro se había llevado a cabo de forma irregular estos presentaban una reclamación. Los pleitos por manifestación resultan mucho más ilustrativos; por una parte, los jueces de la audiencia solían facilitar a los cabezas de familia la presentación de alegaciones y por otra parte, muchos procesos eran iniciados por los propios padres para reclamar la vuelta al hogar de sus hijos.

En la misma línea que llevaba a los padres a recluir a sus hijas, también podían alegar tras los secuestros que sus hijas habían sido engañadas para comprometerse y salir del hogar familiar. El siguiente ejemplo constituye el enunciado más habitual en las solicitudes de manifestación de una hija prófuga:

Teniéndola en su casa y compañía algunas personas injustamente algunas personas la han arrebatado de ella y llevándola consigo con ignorancia y aún contra su voluntad y la tienen oprimida y sin libertad que enteramente la embarazan en usar por su derecho, razón por la cual pide que mediante manifestación se la restituya en su hogar ${ }^{43}$.

Referirse a la ignorancia de las hijas era la mejor baza para conseguir que el tribunal de la Audiencia aprobase realizar una manifestación sin tener que decir que se había fugado de casa. Alegar que una mujer había quedado fuera de la autoridad que le correspondía justificaba una intervención que incluso podía anular otra manifestación realizada por una autoridad menor, por ejemplo bajo la de un corregidor.

Para evitar dudas sobre la legitimidad de secuestros y manifestaciones, los funcionarios debían ser muy escrupulosos en cuanto al ritual de extracción y en el lugar donde se depositaba a la doncella. El ritual de extracción pretendía asegurar que la contrayente no era coartada en su casa, pero si era trasladada por su novio, o este se aproximaba siquiera a ella, habría dudas razonables sobre su neutralidad. La posibilidad de que una mujer tuviese la entereza suficiente como para resistir presiones de su padre o su pareja ni se planteaba. La indefensión asimilada del sexo femenino era una baza importante para garantizar la efectiva libertad de matrimonio de una mujer, pues las autoridades pondrían todos los medios necesarios para mantenerla lejos de cualquier influencia hasta emitir sentencia. Las acciones de las secuestradas nos llevan a considerar que la indefensión de la mujer no era

43. Manifestación de Joaquina Santa Romana solicitada por su padre. AHPZ, Manifestaciones, 1773, J-103325-2.

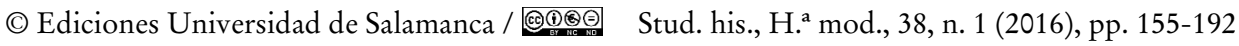


tanto la actitud real de estas secuestradas como la proyección que las autoridades realizaban sobre ellas para evitar que cundiera el ejemplo ${ }^{44}$.

Una vez aceptado el alegato de la parte reclamante, el proceso de remoción era llevado a cabo por el funcionario del tribunal competente. Para los casos de manifestación, la Audiencia de Zaragoza enviaba al portero de la Audiencia junto a un notario que diese fe del acto. Si la manifestación se realizaba desde los corregimientos, era el propio corregidor o el alcalde quien la llevaba a cabo. Los procesos de secuestro eran realizados por un nuncio enviado por el tribunal eclesiástico. El común denominador de estos enviados era que la presencia de un notario se hacía siempre imprescindible. Además, la extracción tenía que ser presenciada por dos testigos normalmente elegidos por el tribunal. El objetivo de todo el ritual era la publicidad del caso para evitar dudas sobre su validez, la comunidad debía enterarse de que la mujer había abandonado legalmente su casa y la tutela de su padre, por lo tanto no había razón alguna para ser discretos.

La actitud de los padres o la condición de las mujeres podía conducir en ocasiones a que la remoción no fuese precisamente discreta. La amenaza de problemas podía llevar al notario a solicitar al alcalde la compañía de las fuerzas del orden. En otros casos, alguna muchacha enferma o con una posición social relevante exigía ser extraída en un carruaje para su mayor recato. Este fue por ejemplo el caso de la manifestación de doña Vicenta de la Cerda, doncella noble de la ciudad de Zaragoza, quien decía haber enfermado porque «le impiden el uso de la libertad natural en cosas lícitas y honestas en grave daño suyo y aún con peligro instante y próximo de la vida» ${ }^{45}$. A juicio del médico que asistía a Vicenta de la Cerda, la presión familiar había provocado efectivamente algún tipo de trastorno. En consecuencia, el tribunal aceptó que se llevase a cabo el secuestro bajo ciertas condiciones especiales:

Mandó a un criado suyo condujese a su cuarto a dicho alguacil acompañado por mí el notario infrascripto y llegando a uno de los interiores de dichas casas hallamos a la mencionada doña Vicenta echada sobre la cama, vestida y preguntándole a presencia de don Antonio Aguirre, médico que la asistía si con efecto como lo tenía pedido quería que se la manifestara respondió inmediatamente que sí y levantándose de la cama la condujo el alguacil a presencia del nominado su padre Don Vicente la Cerda y volviéndole a preguntar ante él si quería ser manifestada respondió que sí (...) y expuso que bien podía el alguacil comisionado desde luego usar de sus facultados y llevarse a su hija manifestada (...) Acto continui, el referido alguacil,

44. Rivera, O.: La mujer y el cuerpo femenino en La perfecta Casada de Fray Luis de León. Delaware, 2006, pp. 12-23.

45. APZ, Manifestación, 1801, 12327-1.

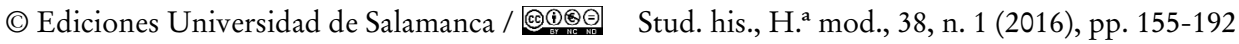


en un coche que había prevenido para ello acompañado de mí, el infrascripto y de los testigos abajo nombrados y aún de Don Antonio Aguirre médico que asistía a la dicha Doña Vicenta que expresó (...) que estaba en disposición de poderla remover y llevarla a donde quisiese ${ }^{46}$.

El desfile de funcionarios, testigos y médicos que entraron en tan noble casa y salieron con la muchacha fue soportado con entereza por el padre de esta. Lo que no pudo tolerar Don Vicente fue que el representante del tribunal volviese a entrar en su casa a buscar una serie de vestidos y muebles de los que dama de tan alta alcurnia no podía prescindir. En efecto, a los pocos días se envió a otro escribano del tribunal acompañado de una criada para recoger estos enseres que solicitó a la madre:

Dijo esta señora que iba a consultarlo con su marido que esperase un poco (...) tras lo cual salió el dicho padre con unos criados y empezó a insultarme diciendo que era un salvaje el dicho escribano y que su casa no era la de ningún zapatero y dijo que había de plantarme en un castillo (presidio) ${ }^{47}$.

La reacción de Don Vicente de la Cerda nos permite ilustrar el problema: su furia no se debía tanto a que la acción del tribunal fuese ilegal, sino al hecho de que la forma de hacerlo menoscababa la honra de su familia; efectivamente, como si fuera un zapatero. Por lo demás, el caballero no mostró mayores problemas y acató la remoción de su hija que había sido llevada a cabo siguiendo el mejor procedimiento y guardando el debido recato.

El rito de cortejo constaba de una serie de pasos muy bien definidos para resguardar el honor de los contrayentes y hacía público el proyecto ante la muy cacareada inconstancia masculina ${ }^{48}$. El secuestro también debía seguir unos pasos muy rigurosos, ya que el riesgo al deshonor era más alto. El procedimiento de remoción incluía la entrada efectiva de los funcionarios en el hogar para sacar a la mujer solicitante, la interrogación de la misma en presencia de sus padres para que no hubiese dudas y la toma de su mano derecha para guiarla fuera de la casa. La entrada en el hogar, así como el papel totalmente pasivo del padre en este proceso sugiere que no era un plato de buen gusto, aunque no tanto como que una hija huyese por la ventana en mitad de la noche.

Los intentos de resistencia por parte de los padres de familia eran poco frecuentes en las manifestaciones y prácticamente inexistentes en los secuestros.

46. Ibidem.

47. Ibidem.

48. Flandrin, J. L.: La moral sexual en Occidente. Barcelona, 1984; Evans, T.: «Unfortunate objects» Lone mothers in Eighteenth-Century-London. Hampshire, 2005, p. 53.

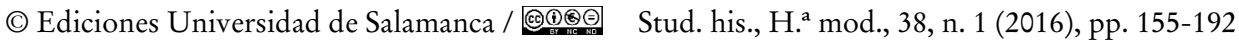


Las familias podían presentar un alegato ante el tribunal donde hacían constar su desacuerdo con el proceso iniciado, pero eran pocos los que se enfrentaban directamente con la autoridad. La razón era que en los casos en los que los padres daban voces contra los jueces o los notarios no lograban detener el proceso, pero sí asegurarse de que toda la comunidad se enteraba de su posición intransigente ${ }^{49}$.

\section{5. «BIEN NECESARIO ES, EL GUARDAR A UNA MUJER»}

Si la extracción era un asunto delicado, una vez la mujer había salido de casa se planteaba un nuevo dilema para determinar dónde ubicarla. El recato de una doncella exigía que se la situase en un lugar seguro donde no pudiera ser deshonrada por ningún hombre en general ni por su prometido en particular ${ }^{50}$. Esta ubicación segura y voluntaria debía estar ratificada tanto por el tribunal como por la mujer depositada. El proceso de remoción especificaba que el notario debía preguntar «si era de su gusto el salir secuestrada», a lo cual la interpelada debía responder afirmativamente. Pasado un día de su encomienda, los funcionarios volvían para interrogarla sobre «si en la casa donde está secuestrada tiene bastante libertad para explicar su ánimo y voluntad sin que haya persona que le persuada ni violente», a lo que la secuestrada debía responder en caso afirmativo: «que está en bastante libertad y que no quiere ni desea tener más» ${ }^{51}$.

Una vez completada la remoción de la persona secuestrada o manifestada, las autoridades procedían a reubicarla temporalmente en un lugar neutral. Las mujeres secuestradas eran encomendadas a un tercero que tendría la misión de custodiar tanto a la persona como la honra de dicha mujer ${ }^{52}$. En la mayoría de los casos, el traslado no implicaba un alejamiento de sus familias. Muy a menudo la casa de la encomienda estaba en su misma localidad o aún en su mismo barrio si se trataba de la ciudad de Zaragoza. El caso más extremo fue el del secuestro

49. Sobre el peligro del cotilleo contra las familias véase: CAPr, B.: When Gossips Meet. Women, Family, and Neighbourbood in Early Modern England. Oxford, 2003, pp. 49-55.

50. La honra de una muchacha era la salvaguarda de su virtud, evitar el contacto carnal a todo precio era lo único que la permitía quejarse de cualquier abuso con legitimidad: MADRID CRUz, M. D.: «El arte de la seducción engañosa: Algunas consideraciones sobre los delitos de estupro y violación en el Tribunal del Bureo. Siglo XviII», Cuadernos de Historia del Derecho, 9, 2002, pp. 121-159.

51. ADZ, 1759, Secuestros, J Lig. 2.

52. El término legal «encomendar» es definido en el Diccionario de Autoridades, Tomo III de 1732 como «Encargar a otro alguna cosa, para que la haga o cuide de ella». El tribunal nombraba a un encomendero ajeno al pleito para que se hiciera cargo del cuidado de la mujer hasta la resolución del conflicto.

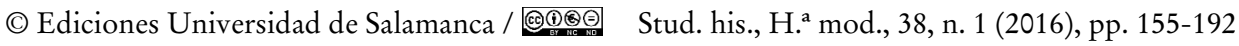


Joaquina Echenique, doncella secuestrada por petición propia, extraída de la casa de sus padres y depositada en una casa sita en la misma calle en la que vivía. Según el registro del proceso, el nuncio eclesiástico Pedro Montero se dirigió la casa en cuestión, «sita en esta ciudad y Calle nueva del Mercado donde habita doña Joaquina Echenique» ${ }^{53}$ y una vez realizado el ritual, «en cumplimiento de lo sobredicho accedió esta y fue personalmente a las casas de la propia habitación de José Arrieta y Feliciana del Buey, cónyuges sitas en esta dicha ciudad y misma calle».

Por muy cerca que estuviesen las casas de los padres de Joaquina Echenique y de José Arrieta y su esposa, no consta que hubiese intromisión en el proceso que terminó en el matrimonio de Echenique con el hombre que ella misma había elegido. El acto de depósito no tenía por lo tanto el objetivo de poner tierra de por medio, sino el de crear una barrera psicológica que impidiese a la familia ejercer su autoridad. El esfuerzo por obtener este efecto explica en parte el despliegue de poder que ejercían los notarios ejecutores convocando guardias, carruajes o traslados de bienes que enviaba un mensaje claro sobre su autoridad a la familia y sus vecinos.

Era importante que el estatus del lugar de acogida estuviese en consonancia con el de la persona secuestrada. Volviendo al caso de la manifestación de Vicenta de la Cerda, la noble doncella no fue llevada como su padre parecía temer a la casa de un zapatero. En su lugar, el tribunal la ubicó en la casa de un regidor de Zaragoza. Lo esencial no era lo alejada que quedase la mujer de su familia, sino lo honrado que fuese el lugar de acogida. Los registros raramente dejan noticia de la ubicación exacta del lugar de depósito, en lugar de ello dan el nombre del amo de la casa y de la persona a la que se encomienda el cuidado de la mujer.

En los casos de mujeres maltratadas, era frecuente que el tribunal las devolviese al hogar familiar o a casa de un hermano que pudiera acogerlas. Si se confirmaba la separación del matrimonio, era posible que la mujer se asentase permanentemente en la casa de su familia. En contraste, las doncellas comprometidas eran acogidas en casas de terceros solo durante unos pocos días y muy raramente en casa de un familiar. Los casos analizados indican que lo más frecuente era ubicar a las muchachas en casa de un vecino del lugar. Familias de confianza contra las que el padre de la secuestrada no pudiese presentar ninguna queja.

53. ADZ, Secuestros, 1761, Lig. 1, J y otros.

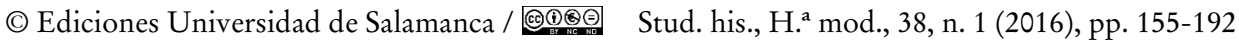




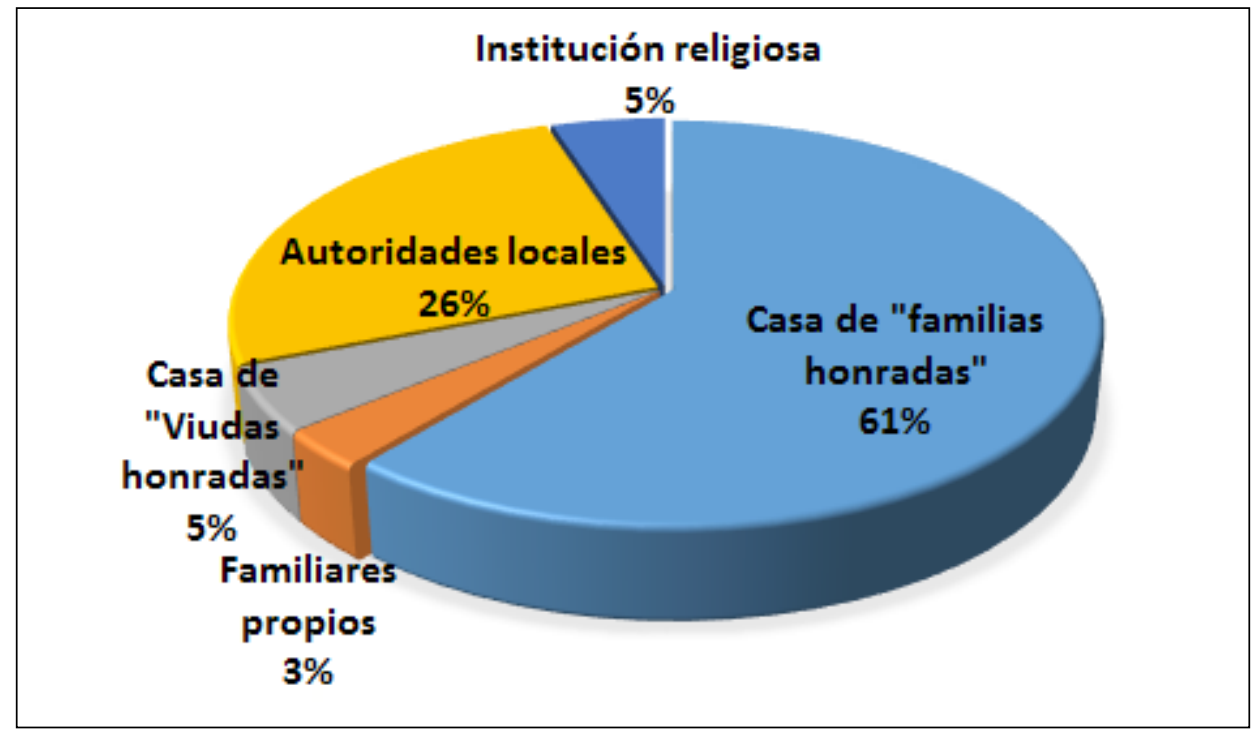

Figura 5: Encomienda de mujeres secuestradas o manifestadas por palabra de matrimonio $(1700-1810)^{54}$.

Como puede observarse en el diagrama, el objetivo era conducir a estas mujeres a hogares donde pudieran asegurar que estaría guardada por una familia, como mínimo, tan honrada como la suya. Los raros casos en los que se permitía a una doncella permanecer en casa de un familiar cercano eran debidos a situaciones especiales. Se trataban de casos en los que, igual que había ocurrido con doña Vicenta de la Cerda, los hermanos ya emancipados habían colaborado con sus hermanas para ayudarlas a salir del hogar familiar donde la vida se les hacía imposible $e^{55}$.

Por norma general, el lugar ideal para ubicar a estas mujeres solteras era una casa honrada que contase con un padre de familia y una esposa o por lo menos

54. Análisis desarrollado mediante los procesos de secuestro (ADZ) y los procesos de manifestación (APZ) exclusivamente de mujeres solteras realizados entre 1700 y 1810. Los procesos suman un total de 263 casos.

55. Este caso resulta extraordinario, tanto la protagonista como su hermano hablan del «irrespirable» ambiente de su hogar familiar, lo cual parece ser cierto pues ambos se esforzaron e incluso se apoyaron para buscarse una vida fuera del hogar en lugar de competir para quedarse con el hogar familiar y con la sustanciosa herencia que sus padres sin duda dejarían al que permaneciese con ellos.

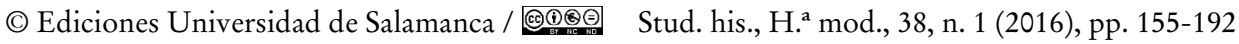


una mujer honrada. La razón era que cada uno de ellos tenía un papel que cumplir como se puede observar analizando un acto de encomienda:

Y después de lo referido, actuó cuasi continuo dentro las casas de la habitación de Juan Clemente Molinos y María Carbonell, cónyuges sitos en la parroquia de la Magdalena y Plazuela de la Trinidad habiendo llegado a ellas el dicho Don Juan Noble, nuncio apostólico del tribunal (...) con la dicha Gracia Cebollero y en presencia del dicho Molinos, notario y en presencia de los testigos nombrados (...) dicho vicario encomendaba y encomendó a la dicha María Carbonell a la persona Gracia Cebollero para que la tenga en su poder, custodiada y cuidarla con obligación de entregarla siempre que la audiencia lo requiriese ${ }^{56}$.

La joven Gracia Cebollero fue trasladada desde su hogar, situado la calle del Barrio Curto en la Parroquia de San Pablo de Zaragoza, hasta la casa de Clemente Molinos, notario del tribunal de la Archidiócesis de Zaragoza y por lo tanto hombre de confianza del nuncio. Es llamativo que no sea al cabeza de familia al que se le confiase la custodia, si no a su esposa. Como mujer honrada de una casa con buena fama, María Carbonell se podía hacer cargo de la muchacha sin que nadie sospechara o lanzara acusaciones contra su recato. Esta convención permitía resguardar doncellas en otros lugares sin presencia masculina como conventos u hogares de viudas honradas.

El tándem que formaban esposas y maridos en estas encomiendas se trataba de hecho de un efectivo resorte de seguridad. Encomendar a estas secuestradas solamente a un varón facilitaba las cosas a cualquiera que quisiese sembrar sospechas sobre su honradez, no era difícil sugerir la pregunta: «¿Qué hacía una muchacha soltera viviendo con un viudo o un solterón?» ${ }^{57}$. Otro tanto podría decirse de la situación contraria. Refugiarse en casa de una viuda honrada era una opción aceptable, pero bastante menos frecuente. La visión popular consideraba que, aunque la mujer fuese mejor custodio de la virginidad de un solterón, la presencia de un varón resultaba de gran ayuda para que la casa no pudiera ser violada por ninguno de los litigantes ${ }^{58}$.

La preocupación de que la casa de deposición fuese honrada no era para menos, un secuestro mal realizado podía cancelar todo el proceso. Por otra parte, la pareja no era la única interesada en que el acto fuese lo más limpio posible.

56. ADZ, 1726, Secuestros, B hasta H LIG 21.

57. Gowing, L.: Common Bodies. Women, Touch and Power in Seventeenth-Century England. Yale, 2003, pp. 90-91; PÉREz TeIjón, J.: Literatura popular y burlesca del siglo XVIII. Salamanca, 1990, p. 120.

58. Lisón Arcal, J.: «La Casa Oscense, Coloquio Hispano-Francés», en Los Pirineos, estudios de Antropología Social e Historia. Madrid, 1986, pp. 11-95.

(C) Ediciones Universidad de Salamanca / ®@ Stud. his., H. ${ }^{a}$ mod., 38, n. 1 (2016), pp. 155-192 
Una vez ejecutado y en una política de hechos consumados, los padres tendían a aceptar esta jugada y, dentro de lo malo, debían asegurarse de que al menos el comportamiento de su hija no escandalizase más de lo que ya lo había hecho. Algo así debió pensar Feliciana del Buey. Esta viuda de Zaragoza vio cómo el tribunal secuestraba a su hija y la depositaba en casa de un médico colegial de Zaragoza. Dicha viuda presentó una queja al tribunal por la falta de recato. Según su declaración, los encomenderos de su hija habían cometido la mayor de las faltas:

dijo y alegó que por cuanto con orden y provisión de dicho ilustrísimo se ha secuestrado a su hija (...) y por cuanto tiene noticias de que en dicha casa es vejada dicha su hija, imbuida y molestada por parte de Lamberto Campos, mancebo a cuya instancia ha sido secuestrada para que contraiga matrimonio y que este la veja a sabiendas de Francisco Larraz y Francisca Pérez. Por ello suplica (...) que se haga remoción de su persona y se la deposite en la casa y compañía que el vicario prefiera ${ }^{59}$.

Además de apartar a la interesada de las presiones de sus padres, la encomienda debía evitar que la pareja se tomase la justicia por su mano. Los padres esperaban que los encomenderos asegurasen la reputación de la muchacha. Muy raramente encontramos denuncias por parte de familiares que rechazasen el proceso en conjunto, lo más habitual es que protestasen por alguna irregularidad particular.

Como era de esperar, Feliciana del Buey, madre de la secuestrada Josepha Xironza, aportó unos testigos que aseguraron haber visto a su prometido introducirse en la casa de este médico zaragozano, y a otros que añadieron además que el prometido tenía una estrecha relación de amistad con los encomenderos. Las acusaciones de esta madre no se basaban tanto en que, según ella, estuviesen forzando a su hija a contraer matrimonio como en «lo público y notorio que el hecho resulta y el escándalo que produce en el lugar estas entradas» ${ }^{60}$. Visitas aparte, la doncella ya había declarado ante su madre que quería ser secuestrada cuando fueron a removerla y posteriormente había repetido esta declaración una vez protegida en casa del propio escribano para evitar dudas. Estas circunstancias pudieron fácilmente llevar a Feliciana a asimilar cuál sería el resultado más probable del secuestro, por lo que en su alegación se preocupó menos de recuperar la autoridad sobre su hija secuestrada y más de que el secuestro se realizase con el recato adecuado.

En términos generales, la remoción de la doncella a una casa honrada solía funcionar sin incidentes dignos de mención. Una vez ejecutado el secuestro de las doncellas, el pleito tendía a resolverse en pocos días. Según el protocolo, nuncio

59. ADZ, 1752, Secuestros, J Lig. 2.

60. Ibidem.

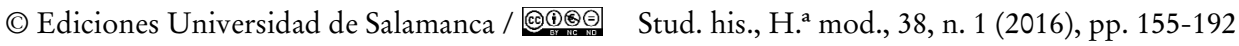


y notario debían volver a la casa en dos ocasiones, dos días distintos para hacer la misma pregunta a la muchacha sobre sus deseos: si contaba con suficiente libertad y cuál era su voluntad ahora que nadie ejercía presión sobre ella. Si la respuesta era que quería contraer matrimonio, el tribunal pasaba a estudiar el estatus de cada uno de los futuros contrayentes para determinar si existía algún tipo de razón para impedir el matrimonio: consanguinidad, ausencia o, sobre todo desde 1776, una fuerte desigualdad de honra ${ }^{61}$.

Esta pesquisa no solía alargar mucho el proceso si ambos contrayentes habitaban en la misma ciudad o localidades cercanas, como ocurría en la mayoría de los casos analizados. Tras la interrogación, el proceso consistía en solicitar un certificado a sus respectivas parroquias sobre su nacimiento y su libertad para contraer matrimonio y en comprobar que no existía entre ambos un parentesco lo bastante cercano como para impedir el matrimonio. La consanguinidad no solía ser un problema, ya que la solicitud de dispensas se trataba de un proceso cotidiano. No obstante, contamos con varios secuestros que certificaban la necesidad de una dispensa. En la mayoría de los casos, la pareja ya había solicitado o incluso recibido la dispensa en el momento de solicitar el secuestro por lo que las diócesis daban el visto bueno a la mayoría de estos matrimonios entre parientes ${ }^{62}$.

El proceso de manifestación seguía unos términos similares en cuestión de remoción de doncellas y encomienda. No obstante, su interpretación del matrimonio estaba mucho más ligada al reconocimiento de la autoridad del cabeza de familia y en consecuencia era muy frecuente que el proceso fuese una herramienta en manos de los padres para detener el matrimonio de sus hijos. No hay que confundir la manifestación con una extensión de la Patria Potestas, en ningún momento solicitaban que su hija fuese detenida por desobediencia. En lugar de ello, se solicitaba que fuese rescatada de aquellos que la habían engañado, «por su naturaleza débil y poco entendimiento». Esta peculiar interpretación de la protección femenina llevaba a que en muchos casos las mujeres a extraer no estuvieran de acuerdo con la necesidad de ser protegidas. Este fue el caso de la manifestación de Joaquina Santa Romana, doncella de Zaragoza. Como en otros casos, el portero de la Audiencia se dirigió a la casa en la que supuestamente estaba retenida para ponerla bajo custodia, o al menos intentarlo:

61. Chacón Jiménez, F. y Méndez VÁzquez, J.: «Miradas sobre el matrimonio en la España del último tercio del siglo XviII", Cuadernos de Historia Moderna, 32, 2007, pp. 61-85.

62. Alfaro Pérez, F. J. y Salas Auséns, J. A.: «Dispensas de consanguinidad en la diócesis de Zaragoza (1700-1833)», en Contreras, J. y SÁnchez IbáñEz, R.: Familias, poderes, instituciones y conflictos. Murcia, 2011, pp. 493-510.

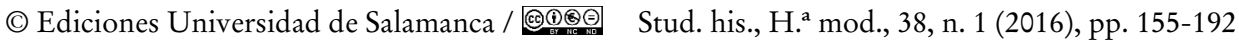


Agustín San Juan, portero de la Real Audiencia pasó con el notario Juan Laborda a manifestar a ésta (...) y dijo que en su cumplimiento la manifestaba (...) para depositarla a orden del tribunal. A lo que esta respondió una y muchas veces (que) no quería salir de la casa y compañía en que se hallaba, porque en ella estaba sin opresión y con entera libertad y que primero la habrían de llevar arrastrando desde donde estaba sentada o romperle las piernas que salir de allí y que si la tocaban se echaría por el balcón antes de moverse del cuarto ${ }^{63}$.

Enfrentados a esta situación de fuerza mayor, notario y portero optaron por replegarse y volver a la mañana siguiente con los necesarios refuerzos para llevarse a la adolescente. Esta explosión de furia para evitar que la sacaran de casa de su prometido no era lo más común. Sin embargo, no hay duda de que Joaquina Santa Romana había dejado su hogar sin engaño alguno y estaba firmemente dispuesta a llevar a término su propio proyecto vital.

El caso de Joaquina resulta excepcional dentro de las manifestaciones ordenadas por los padres. En la mayor parte de los casos los jóvenes requeridos por la Audiencia tendían a aceptar la reclamación de su padre, independientemente del sexo del manifestado. Se puede llegar a apreciar la importancia de la manifestación al comprobar cómo en algunos casos llegó a servir para extraer a un joven de la prisión episcopal donde esperaba para ser procesado por abandonar a su prometida tras dejarla embarazada. La manifestación de Francisco Antonio Torrijos realizada en 1789 fue la respuesta a una orden de secuestro expedida por el tribunal diocesano de Zaragoza. Si atendemos a la Figura 3, veremos cómo el secuestro de Torrijos se trata de uno de los 46 secuestros ordenados contra varones por incumplir una promesa matrimonial. En el caso de Torrijos, su prometida Manuela Jarreta había solicitado su traslado a la prisión episcopal con el siguiente argumento:

Que bajo palabra de casamiento se conocieron carnalmente y tuvo como resultado quedar embarazada. (...) Ante gentes fidedignas dicho Torrijos resolvió el ratificar que se iba a casar con ella que es mujer honesta y recatada (...) Pero dicho Antonio se ha excusado y excusa a cumplir con dicha palabra dejando con poco temor de Dios expuesto y abandonado el honor de la suplicante ${ }^{64}$.

Este caso expone un conflicto por estupro, también conocido como burla a raíz de las famosas hazañas de Don Juan Tenorio. Los pleitos por incumplimiento de esponsales son otro de los casos más frecuentes recogidos en el tribunal diocesano

63. Ibidem.

64. APZ, Manifestaciones, 1789, 12494-11.

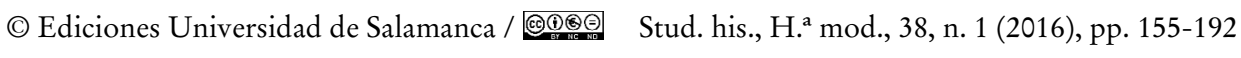


DANIEL BALDELLOU

TRANSGRESIÓN Y LEGALIDAD EN EL CORTEJO DEL SIGLO XVIII:

EL SECUESTRO DE MUJERES EN LA DIÓCESIS DE ZARAGOZA

de Zaragoza ${ }^{65}$. Manuela Jarreta logró que el obispado ordenase el arresto del infractor. No obstante, la familia del mismo contraatacó invocando una manifestación alegando opresión y enfermedad:

Se hallaba mi parte en dichas cárceles de corte gravísimamente enfermo por las presiones que ha sufrido en las del citado tribunal eclesiástico y necesitando hacer constar su gravedad ante este por tanto le sirva mandar médicos colegiados para atender inmediatamente su estado ${ }^{66}$.

La confrontación del proceso de secuestro y manifestación quedó, en este caso, en tablas. Antonio Torrijos aceptó la manifestación que le liberó de la cárcel, pero poco después se presentó ante la misma autoridad que lo había secuestrado para pactar plegarse a las exigencias de Jarreta:

Juro e igualmente se ratifica en ello Manuela Jarreta, actora de la demanda matrimonial y presente, que sea de este acto a fin de poderse verificar el matrimonio que ambos desean y usando de dichos poderes especiales me separo a nombre de mi parte de esta manifestación consintiendo a la petición de aquella ${ }^{67}$.

Antonio Torrijos no realizó ninguna acción extravagante. Había salido de la prisión episcopal, pero su prometida tenía suficientes testimonios como para que el tribunal diocesano sentenciase su matrimonio. El acusado optó por adelantarse y acordar una declaración conjunta con Manuela Jarreta en la que ponían fin al pleito y a los procesos de secuestro y manifestación. En los pleitos por incumplimiento de esponsales era muy frecuente que las partes llegasen a un acuerdo que ahorraba tiempo, dinero y evitaba que su futuro fuese decidido por una autoridad ajena.

La manifestación era, en ciertos casos, un recurso eficaz contra el secuestro; si se lograba convencer al tribunal de que este se había llevado a cabo de forma irregular. No existían provisiones sobre qué ocurría cuando estas dos autoridades chocaban. En los pocos casos que ocurría, el éxito solía ser depender de lo enérgica que fuese la resolución de los comprometidos para mantener su proyecto. Por otra parte, los pleitos por secuestro eran bastante más regulares en su ejecución y en su número, por lo que probablemente se trataban del recurso habitual mientras que la manifestación se usaba en circunstancias muy concretas. Entre ellas estarían

65. En la misma línea de investigación en la que se enmarca este artículo se han analizado un total de 249 pleitos por incumplimiento de esponsales. Respecto al desarrollo de dichos pleitos véase: Baldellou Monclús, D.: «Los conflictos matrimoniales en las familias y estructuras de poder del alto Aragón en el siglo XvIII", Tiempos modernos: Revista Electrónica de Historia Moderna, 8:29, 2014, en: http://www.tiemposmodernos.org/tm3/index.php/tm/article/view/404/431.

66. APZ, Manifestaciones, 1789, 12494-11.

67. Ibidem.

(C) Ediciones Universidad de Salamanca / ®@ Stud. his., H. ${ }^{a}$ mod., 38, n. 1 (2016), pp. 155-192 
los casos de padres apelando contra secuestros mal realizados o escandalosos y algunas situaciones en las que los declarantes reconocían temer por la parcialidad del tribunal eclesiástico: «Que sus parientes severamente la castigan y le impiden contraer dicho matrimonio y aún intentan valerse de la autoridad del vicario general del obispado de Huesca para continuar sus opresiones» ${ }^{68}$.

Las sentencias de estos secuestros terminaban en su mayoría de forma positiva para las parejas comprometidas. El tribunal diocesano primaba el libre albedrío sobre cuestiones como las diferencias estamentales o la oposición familiar. La mayoría de los secuestros se despachaban rápidamente siguiendo el mismo proceso: comprobación del origen de los contrayentes, ratificación de que no existía consanguinidad ni impedimento alguno y orden a la parroquia, frecuentemente la del novio, que pronunciase misa nupcial. Esta sentencia venía acompañada normalmente de una carta del presbítero ratificando la ejecución de la orden y especificando el número de moniciones que debían darse ${ }^{69}$.

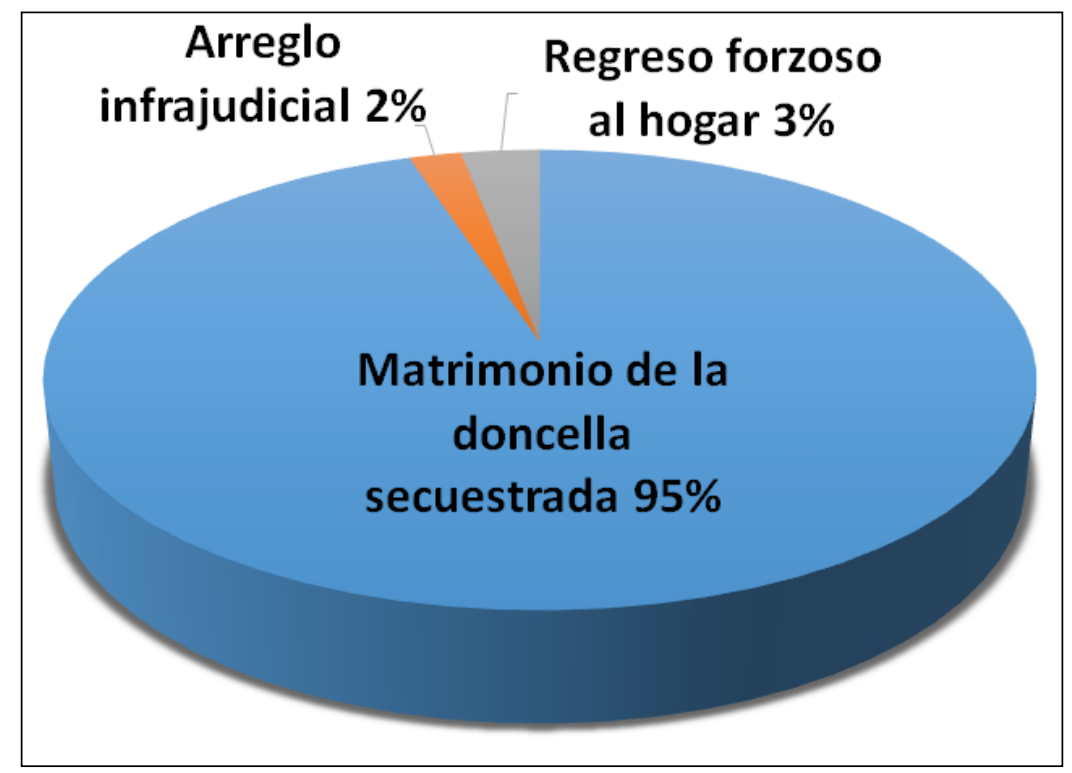

FIgURA 6: Resolución de los secuestros de mujer comprometida (233 casos).

68. APZ, Manifestación, 1728, 13403-22.

69. Iglesias Estepa, R.: «Violencia física y verbal en la Galicia de finales del Antiguo Régimen», Ciencias Sociais e Humanidades, 19, 2007, pp. 135-157.

(C) Ediciones Universidad de Salamanca / ®@ Stud. his., H. ${ }^{a}$ mod., 38, n. 1 (2016), pp. 155-192 


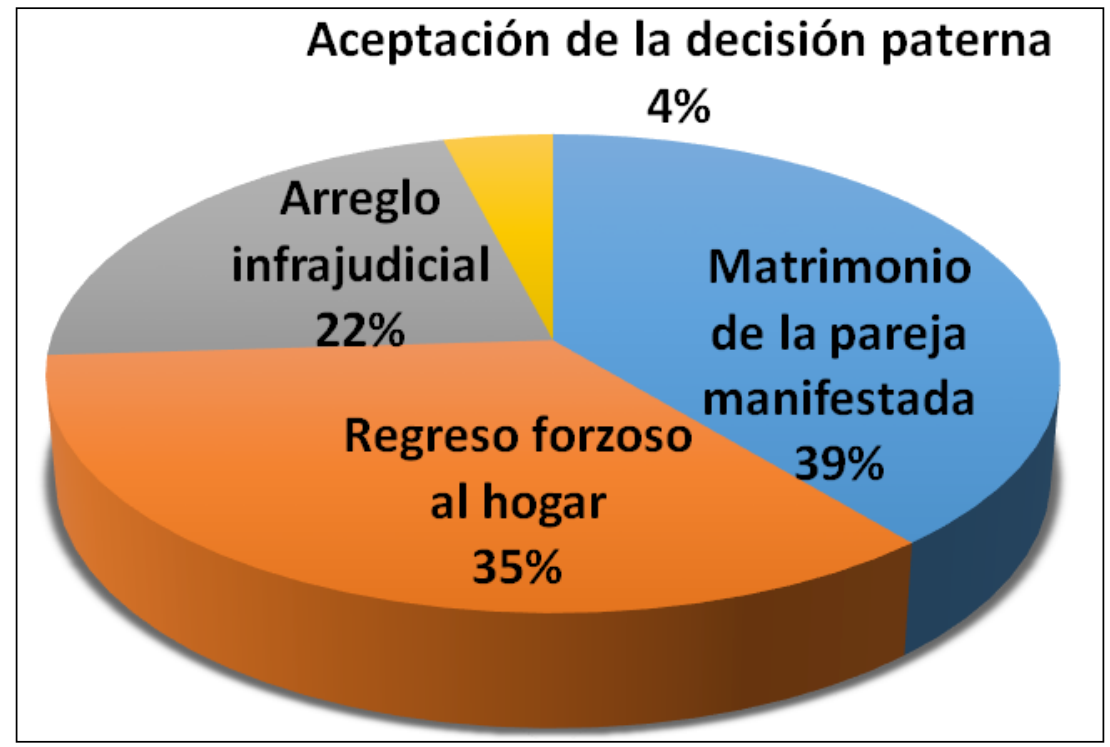

FIgURA 7: Resolución de las manifestaciones de mujer comprometida (60 casos $)^{70}$.

Como puede observarse en las figuras 6 y 7 , hay una diferencia importante en el criterio que seguían los jueces eclesiásticos y reales a la hora de resolver conflictos similares. A diferencia de otros pleitos que tendían a solucionarse mediante un acuerdo entre las partes, la mayoría de manifestaciones y secuestros terminaban con una sentencia en firme. Se trataban de litigios rápidos que se resolvían de media en pocos días y donde actos más costosos como careos, interrogación de testigos o alegaciones de un procurador no eran necesarios: denuncia, remoción, encomienda, interrogatorios y sentencia solían ser los únicos pasos. Por otra parte, las parejas que solicitaban este proceso solían tener preparados todos los requisitos que pedía el tribunal: promesas de matrimonio bien conocidas y a menudo por escrito, un mínimo de dos testigos que ratificasen su relación y, cuando eran necesarias, las dispensas o probanzas de libertad.

Las sentencias de secuestros y manifestaciones no declaraban libre a una mujer extraída de su hogar, declaraban si era legítimo o no su matrimonio. En caso de serlo, la sentencia consistía en ordenar a la pareja que solemnizase ante el altar su unión. En caso contrario, ordenaban el regreso de la joven a su hogar y anulaban

70. Análisis desarrollado mediante los procesos de secuestro (ADZ) y los procesos de manifestación (APZ) entre 1700 y 1810.

(C) Ediciones Universidad de Salamanca / @@@ Stud. his., H. ${ }^{\text {a }}$ mod., 38, n. 1 (2016), pp. 155-192 
cualquier contrato de esponsales que hubiese justificado el secuestro. El tribunal eclesiástico tenía la peculiaridad añadida de sentenciar el matrimonio y especificar cómo y cuándo debería llevarse a cabo. Para este tribunal, el secuestro y el matrimonio de la mujer secuestrada no constituían procesos distintos, la mayor parte de los secuestros terminaban con una sentencia similar a la siguiente:

Que recibida en el tribunal la ratificación de las parroquias de las partidas bautismales de ambos, el infrascripto ordena al párroco de San Felipe que sin preceder amonestación alguna de las tres canónicas dispuestas por el Santo Concilio de Trento se despose por palabras legítimas y de presente a estos dos y que así conste en sus quinque libri ${ }^{71}$.

El tribunal diocesano no dejaba nada al azar, la sentencia no solo ordenaba a la pareja contraer matrimonio, también hacía llegar la orden al párroco que debía realizar la ceremonia y se aseguraban de que constaría en todos los registros legales a fin de hacer la unión inapelable. Era también prerrogativa del tribunal diocesano decidir si dispensaban a las parejas de las tres amonestaciones, normalmente obligatorias. La autoridad eclesiástica utilizaba las amonestaciones para asegurar que se trataba de un matrimonio público y que no había ningún impedimento que obstruyese el enlace. Si las parejas superaban un proceso de secuestro especialmente complejo, los jueces diocesanos daban por demostrada la compatibilidad de los contrayentes y preferían agilizar la celebración del matrimonio para evitar nuevos impedimentos. A falta de más estudios sobre este proceso, el trabajo de otros autores y en otras diócesis sugiere que el funcionamiento del secuestro era similar en otros territorios españoles y que constituía un recurso eficiente para aquellas situaciones en las que la negativa de un padre impedía una unión que, según la costumbre del común, entraba dentro de lo razonable ${ }^{72}$.

Los tribunales de la Audiencia de Zaragoza se mostraban mucho más reacios a permitir el matrimonio de los manifestados. Es difícil asegurar cuál era la razón de esta diferencia, posiblemente se debiese a que el tribunal diocesano, más vinculado al derecho canónico, diese más importancia a la libertad de matrimonio por encima de la patria potestas. Fuera como fuese, un número mucho mayor de remociones llevadas a cabo en forma de manifestación terminaron por conducir a la anulación del compromiso matrimonial. El resultado favorable a los cabezas de familia podía darse de dos formas posibles, bien con una sentencia que desautorizaba el compromiso de la pareja o simplemente con la aceptación de los hijos del

71. ADZ, Secuestros, 1774, secuestro de Doña María Joaquina Marín, M-Lig 2 (caja 2).

72. Estudios sobre este proceso en Cataluña pueden localizarse en Costa, M.: Conflictos matrimoniales y divorcio en Cataluña: 1775-1833. Tesis doctoral presentada no publicada, Institut Universitari d'Història Jaume Vicens Vives, 2007.

(C) Ediciones Universidad de Salamanca / ®@ Stud. his., H. ${ }^{a}$ mod., 38, n. 1 (2016), pp. 155-192 
designio paterno. No obstante, a diferencia de los secuestros, las manifestaciones son órdenes personales. Una manifestación invocada por los padres, podía hacer que los hijos volviesen a casa, pero no imposibilitaba el uso de otras estrategias para mejorar su situación.

\section{CONCLUSIONES: MATRIMONIO CONSENSUADO}

Aun teniendo en cuenta los casos de manifestaciones en los que primaba la voluntad paterna, el resultado general de las remociones solía ser de un rotundo éxito para las parejas que utilizaban el secuestro y la manifestación para lograr emanciparse del control familiar. Un matrimonio podía realizarse con la oposición de la familia, sin embargo era muy difícil obligar a dos individuos que se odiaban a contraer matrimonio, pues más tarde o más temprano tendrían que declarar su voluntad ante el sacerdote. Los matrimonios totalmente forzados tendían a fracasar, como atestiguan los secuestros destinados a esposas maltratadas. Se daba por hecho que la dirección de los padres era beneficiosa, pero si esta conducía a un matrimonio de riesgo, el derecho a la resistencia de los hijos solía ser considerado legítimo. Los secuestros y manifestaciones constituían un recurso razonablemente rápido para desbloquear proyectos matrimoniales. El precio era que estos enlaces debían encajar dentro de las estructuras básicas de emparejamiento que garantizaba una continuidad del orden social.

La mayoría de las sentencias legitiman la voluntad de los hijos, pero los registros notariales no dicen nada más sobre cómo encajaron las familias estos resultados. Probablemente, tras conocer la sentencia, dejarían de intentar impedir el matrimonio, pero no por ello estaban obligados a ponérselo más fácil. El elevado número de secuestros de doncellas y aún más el elevado número de sentencias positivas para la pareja no significa que imperase el matrimonio libre. Uno de los aspectos más polémicos de esta autoridad era precisamente que aun con una orden matrimonial, las familias contaban con muchas alternativas para hacerles el boicot, especialmente en cuanto a la dotación y el reparto de la herencia.

El tribunal eclesiástico podía en efecto legitimar un matrimonio contra la voluntad paterna, pero fundar una familia sin recursos era una cuestión igual o más transgresora para la comunidad que hacerlo contra la voluntad de los padres. No es posible determinar con seguridad cuántos matrimonios podían realizarse sin dote o en cuántos de estos casos los padres permitían que sus hijos se casasen empobrecidos. El problema no era desde luego ajeno a las autoridades que dirimían este tipo de conflictos. Las sentencias de muchos pleitos por estupro o por libertad de matrimonio no terminaban solamente con la orden de ejecutar el enlace, sino

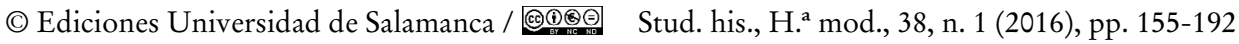


que solían acompañarse de la orden de que «se la dote adecuadamente y según las posibilidades de su casa» ${ }^{73}$.

La preocupación por evitar uniones inaceptables para el tejido social era en esencia la que defendía el derecho de los padres a intervenir en los matrimonios de sus hijos. En ocasiones, los pleitos y especialmente las viscerales declaraciones de cada parte pueden arrojar la visión de una sociedad dividida en bandos irreconciliables; en realidad, una comunidad en conflicto continuo tan virulento como el que parece extraerse de los pleitos sería una sociedad ingobernable. Los padres competían con sus hijos por el control de sus vidas, las familias competían entre sí por cargos y posición social y las autoridades lo hacían por el control de la comunidad. Pero competencia no es sinónimo de conflicto. Tras analizar las estructuras de las comunidades del obispado de Turín, Giovanni Levi concluía que no podía plantearse una explicación simplista del conflicto con facciones y mentalidades claras, sino que la solidaridad y el conflicto se mezclaban en la realidad, haciendo difícil la construcción de un modelo ${ }^{74}$. El camino al matrimonio muestra una composición igual de compleja que estas relaciones: existían principios morales enfrentados que cada individuo enunciaba según sirviesen a su interés; ni siquiera podemos hablar de principios seguidos a rajatabla por los tribunales que los defendían y, sobre todo, hay que tener en cuenta que estas adscripciones morales no eran más que el campo en el que se desplegaban variables como el afecto, los recursos económicos, la posición social, los contactos personales o la previsión de futuro de cada una de las partes.

El secuestro y la manifestación eran herramientas para hacerlas valer cuando las negociaciones quedaban bloqueadas, pero resultaría reduccionista pensar que esta era la forma de actuación habitual. Los tribunales ejecutaban estos procesos buscando ante todo la discreción y no poner en duda la honra de los protegidos y sus familias. El escándalo ante un secuestro era inevitable, pero bien realizado abortaba el riesgo de que el conflicto terminase con alternativas más peligrosas como un matrimonio oculto, una fuga de los hijos o violencia doméstica. Dentro de lo transgresor, los recursos legales de manifestación y secuestro garantizaban que el conflicto terminaría con el menor de los males. Por otra parte, la sentencia del tribunal iba dirigida a reestablecer el orden preestablecido: los hijos se casarían dentro de los estándares que mandaba la iglesia, los padres deberían apoyar

73. Almárcegui, A.: «Pequeña nobleza rural, sistema de herencia y estructura de la propiedad de la tierra en Plasencia del Monte (Huesca). 1600-1855», en Chacón Jiménez, F. y Hernández Franco, J. (eds.): Poder, familia y consanguinidad en la España del Antiguo Régimen. Barcelona, 1992, pp. 71-106.

74. Levi, G.: La herencia inmaterial: la historia de un exorcista piamontés del siglo XVII. Madrid, 1990, pp. 8-13.

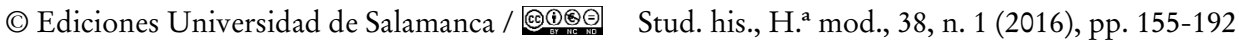


el matrimonio aunque solo fuese en lo mínimo y la evolución de hija a esposa se realizaría bajo una supervisión, como mínimo, tan estricta como la de un padre.

Si los vínculos familiares componían el tejido social más básico del Antiguo Régimen, es lógico pensar que se vieron afectadas por las reglas enunciadas por Thompson y Levi y que antes de hablar de matrimonio libre y matrimonio forzado, probablemente la norma que deberíamos tener presente sea la de matrimonio consensuado. Un consenso que llegaría después de que cada parte plantease sus exigencias para conseguir lo que, desde su propio punto de vista, era más adecuado para su familia, ya fuese la que tenían o la que pensaban fundar. Las reglas del juego no escritas permitían atemperar conflictos y garantizar la viabilidad de la unión, así como permitir que la comunidad tuviese la autoridad de juzgar un proceso acerca del cual vecinos y familiares se consideraban plenamente autorizados a actuar.

\section{BibLIOgRAFÍA}

Alfaro Pérez, F. J. y Salas Auséns J. A.: «Dispensas de consanguinidad en la diócesis de Zaragoza (1700-1833)», en Contreras, J. y SÁNCHEz Ibá̃̃̃z, R.: Familias, poderes, instituciones y conflictos. Murcia, 2011, pp. 493-510.

BAldellou Monclús, D.: «Los conflictos matrimoniales en las familias y estructuras de poder del alto Aragón en el siglo XVIII», Tiempos Modernos: Revista Electrónica de Historia Moderna, 8, 2014, en: http://www.tiemposmodernos.org/tm3/index.php/ $\mathrm{tm} /$ article/view/404/431.

Baldellou Monclús, D.: «El honor de los padres y la libertad de los hijos: la aplicación del veto paterno a los matrimonios transgresores en la España preliberal», en ALfARo Pérez, F. (coord.): Familias rotas. Conflictividad familiar a finales del Antiguo Régimen. Zaragoza, 2014, pp. 55-104.

Bolufer Peruga, M.: «Mujeres y hombres en el espacio del reformismo ilustrado: debates y estrategias», en Jornada Mujer i ciudadanía: del Antigno Régimen a la Revolución liberal. Departament Història Moderna i Contemporània, Instituto de la Mujer, 2003, en https://www.academia.edu/5525810/Mujeres_y_hombres_en_los_espacios_del_reformismo_ilustrado (última consulta: 27/01/2015).

Bolufer Peruga, M.: «Lo íntimo, lo doméstico y lo público: representaciones sociales y estilos de vida en la España Ilustrada», Studia Historica. Historia Moderna, 19, 1998, pp. 85-116.

BONFIELD, Ll.: «Avances en la legislación familiar europea», en KerTzer, D. y BARBAgLI, M. (Comp.): La vida familiar a principios de la era moderna (1500-1789), Historia de la familia europea. Volumen I. Barcelona, 2002, pp. 153-204.

Candau Chacón, M. L.: «Entre lo permitido y lo ilícito: la vida afectiva en los Tiempos Modernos», Tiempos Modernos, 18, 2009, pp. 11-17.

Candau Chacón M. L.: Los delitos y las penas en el mundo eclesiástico sevillano del XVIII. Sevilla, Diputación Provincial de Sevilla, 1993.

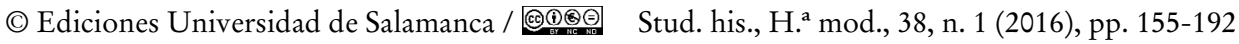


DANIEL BALDELLOU

TRANSGRESIÓN Y LEGALIDAD EN EL CORTEJO DEL SIGLO XVIII:

EL SECUESTRO DE MUJERES EN LA DIÓCESIS DE ZARAGOZA

Capp, B.: When Gossips Meet. Women, Family, and Neighbourbood in Early Modern England. Oxford, 2003.

Chacón Jiménez, F. y Méndez VÁzquez, J.: «Miradas sobre el matrimonio en la España del último tercio del siglo XVIII", Cuadernos de Historia Moderna, 32, 2007, pp. 61-85.

Costa, M.: Conflictos matrimoniales y divorcio en Cataluña: 1775-1833. Tesis doctoral presentada en la Universitat Pompeu i Fabra. Barcelona, 2007.

Dou y Bassols, R. L. de: Instituciones del derecho público general de España con noticia particular de Cataluña, y de las principales reglas de gobierno en qualquier estado. Madrid, 1800-1803.

Pascua Sánchez, M. J. de la: «Una aproximación a la historia de la familia como espacio de afectos y desafectos en el mundo hispánico del setecientos», Chronica nova: Revista de historia moderna de la Universidad de Granada, 27, 2000, pp. 131-166.

Ferrante, L.: «L'onore ritrovato. Donne nella Casa de Socorso di San Paolo de Bologna (sec. XVI-XVII)», Quaderni Storici, 53, 1983, pp. 500-523.

Ferraro, J. M.: Marriage Wars in Late Renaissance Venice. Oxford, 2001.

FLANDRIn, J. L.: La moral sexual en occidente. Barcelona, 1984.

García Martínez, M. I.; Álvarez Faedo, M. J. y Simón-Schuhmacher, L.: La educación de la mujer en el siglo XVIII en España e Inglaterra. Lewiston, 2005.

Gaudemet, J.: El matrimonio en Occidente. Madrid, 1993.

Ghirardi, M.: «El encierro femenino como práctica. Notas para el ejemplo de Córdoba, Argentina, en el contexto de Iberoamérica de los siglos XVIII y XIX», Revista de Historia Social y de las Mentalidades, 14, 2010, pp. 73-101.

Gowing, L.: Common Bodies. Women, Touch and Power in Seventeenth-Century England. Yale, 2003, pp. 90-91.

Iglesias Estepa, R.: «Las quiebras del orden cotidiano: comportamientos criminales en la sociedad gallega de fines del Antiguo Régimen», Obradoiro de Historia Moderna, 13, 2004, pp. 277-302.

Iglesias Estepa, R.: «Violencia física y verbal en la Galicia de finales del Antiguo Régimen», Ciencias Sociais e Humanidades, 19, 2007, pp. 135-157.

Imizcoz Benza, J. M.: «Familia y redes sociales en la España Moderna» en Lorenzo PinAR, F. J. (ed.): La familia en la Historia. Salamanca, 2008, pp. 135-186.

Ingram, M.: Church Courts, Sex and Marriage in England, 1570-1640. Cambridge. 1987.

Juncal Campo Guinea, M.: «La actividad procesal de los tribunales de justicia en Navarra en el estudio de cambios y permanencias (siglos XVI-XIX)», Cuadernos de Investigación Histórica, 18, 2001, pp. 87-100.

Juncal Campo Guinea, M.: «Los procesos por causa matrimonial ante el tribunal eclesiástico de Pamplona en los siglos XVI y XVII», Príncipe de Viana, 202, 1994, pp. 377-390.

Laliena Corbera, C.: «Honor, vergüenza y estatus en las familias serviles del Pirineo Central en la Edad Media», en Iglesia Duarte, J. I. de la (coord.): La familia en la Edad Media: XI Semana de Estudios Medievales, Nájera, del 31 de julio al 4 de agosto de 2000. Instituto de Estudios Riojanos, 2001, pp. 179-208.

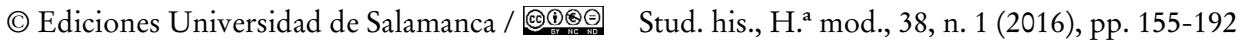


DANIEL BALDELLOU

TRANSGRESIÓN Y LEGALIDAD EN EL CORTEJO DEL SIGLO XVIII:

EL SECUESTRO DE MUJERES EN LA DIÓCESIS DE ZARAGOZA

LanzInger, M. y SARTI, R.: Nubili e Celibi tra scelta e costrizione (Secoli XVI-XX). Udine, 2006.

LARripa, J. F.: Ilustración a los cuatro procesos forales de Aragón. Edición de BoneT Navarro, Á. y Redondo Veintemillas, G., Zaragoza, Cortes de Aragón, 1985.

Levi, G.: La herencia inmaterial: la historia de un exorcista piamontés del siglo XVII. Madrid, 1990, pp. 8-13.

Lisón Arcal, J.: «La Casa Oscense, Coloquio Hispano-Francés», en Los Pirineos, estudios de Antropología Social e Historia. Madrid, 1986, pp. 11-95.

Lombardi, D.: Matrimoni di antico regime. Bolonia, Il Mulino, 2001.

Lombardi, D.: «Privilegios jurídicos y relaciones de vecindad en la formación de la pareja en la Italia Moderna», Obradoiro de Historia Moderna, 21, 2012, pp. 9-27.

Lorenzo Pinar, F. J.: «Conflictividad social en torno a la formación del matrimonio (Zamora y Toro en el siglo XVI», Studia histórica. Historia Moderna, 13, 1995, pp. 131-154.

Madrid Cruz, M. D.: «El arte de la seducción engañosa: Algunas consideraciones sobre los delitos de estupro y violación en el Tribunal del Bureo. Siglo XviII», Cuadernos de Historia del Derecho, 9, 2002, pp. 121-159.

Mantecón Tomás, A.: «El peso de la infrajudicialidad en el control del crimen durante la Edad Moderna», Estudis: Revista de Historia Moderna, 28, 2002, pp. $43-76$.

Martín Gaite, C.: Usos amorosos del XViri en España. Barcelona, 1988.

Morales Arrizabalaga, J.: «El justicia de Aragón en el siglo XVIII: la transición de una institución jurisdiccional a un símbolo político», en Actas del Octavo encuentro de estudios sobre el Justicia de Aragón. Zaragoza, 2008, pp. 45-78.

Morant Deusa I. y Bolufer Peruga, M.: «Sobre la razón, la educación y el amor de las mujeres: mujeres y hombres en la España y en la Francia de las luces», Studia Historica. Historia Moderna, 15, 1996, pp. 179-208.

Moreno Almárcegui, A.: «Pequeña nobleza rural, sistema de herencia y estructura de la propiedad de la tierra en Plasencia del Monte (Huesca). 1600-1855», en CHAcón Jiménez, F. y Hernández Franco, J. (eds.): Poder, familia y consanguinidad en la España del Antiguo Régimen. Barcelona, 1992, pp. 71-106.

Morgado García, A.: «Los manuales de confesores en la España del siglo XVIII», Cuadernos Dieciochistas, 5, 2004, pp. 123-145.

O'Hara, D.: Courtship and Constraint. Rethinking the Making of Marriage in Tudor England. Manchester, 2002.

Pascua Sánchez, M. J. de la: «Una aproximación a la historia de la familia como espacio de afectos y desafectos en el mundo hispánico del setecientos», Chronica Nova: Revista de Historia Moderna de la Universidad de Granada, 27, 2000, pp. 131-166.

Pérez, Teijón, J.: Literatura popular y burlesca del siglo XVIII. Salamanca, 1990.

Rey Castelao, O.: «Mujeres en la economía campesina», en Morant, I. (coord.): Historia de las mujeres en España y América Latina, Vol. 2. Barcelona, 2005, pp. 263-286.

Rivera, O.: La mujer y el cuerpo femenino en La perfecta Casada de Fray Luis de León. Delaware: Juan de la Cuesta, 2006.

(C) Ediciones Universidad de Salamanca / ®@ Stud. his., H. ${ }^{a}$ mod., 38, n. 1 (2016), pp. 155-192 
Seidel Menchi, S.: «La svolta di Trento. Ricerche italiane sui processi matrimoniali», Popolazione e storia, 2, 2004, pp. 21-32.

SHORTER, E.: The Making of Modern Family. Londres, 1977.

Torremocha Hernández, M.: «El matrimonio y la relación de los cónyuges en la Castilla postridentina (en la literatura de la época)», en Bestard J. y PÉrez, M.: Familia, valores y representaciones. Murcia, 2010, pp. 155-178.

UsunÁrIz GARAYOA, J. M.a: «La violencia doméstica en la España de los siglos XVI y XVII: el ejemplo del reino de Navarra», en Escudero, J. M. y Roncero, V. (coord.): La violencia en el mundo hispánico en el Siglo de Oro. Madrid, 2010, pp. 375-394. 